


\title{
Housing Prices, Inter-generational Co-residence, and "Excess" Savings by the Young: Evidence using Chinese Data
}

\author{
Mark R. Rosenzweig \\ Yale University and NBER \\ Junsen Zhang \\ Chinese University of Hong Kong
}

August 2019

\begin{abstract}
In many countries of the world the co-residence of young adults aged 25-34 with their parents is not uncommon and in some countries the savings rates of these age groups exceed those of the middle-aged contrary to the standard model of life-cycle savings. In this paper we examine the role of housing prices in affecting the living arrangements of adult family members and their individual savings rates by age. Using unique data from China that enable the re-construction of whole families and identify individual savings regardless of who within the family co-resides in the same household, and exploiting the Chinese government rules determining the supply of land for residential housing, we find that increases in housing prices significantly increase inter-generational co-residence and elevate the savings rates of the young relative to the middle-aged, conditional on income, in part due to the subsidies to the young from sharing housing with parents. Based on our estimates of the effects of housing prices on co-residence and the effects of co-residence on individual savings, we find that the savings rates of the young in China would be $21 \%$ lower if housing prices were at the same ratio to disposable incomes as that observed in the United States.
\end{abstract}

Keywords: savings, family, housing price, co-residence 


\section{Introduction}

In this paper we seek to quantify the role of housing prices in affecting the living arrangements of adult family members and their life-cycle patterns of savings. Our study is in part motivated by the fact that in many countries of the world rates of inter-generational co-residence among young adults, those aged 25-34, are very high and their savings rates appear to be higher than those of the middle-aged. These "excess" savings rates by the young are in contradiction to the canonical life-cycle model of savings. The life-cycle savings model has been the canonical model of savings in economics for a very long time (Browning and Crossley, 2001; Jappelli and Modigliani, 2005). The framework describes the savings behavior of an individual in a world in which incomes vary by age and are subject to transitory shocks. Empirical tests of that model and tests of other models of individual savings behavior (e.g., Dynan et al., 2004), however, use household data that provide the aggregation of savings of all members of a household. If all households consisted solely of married couples, who tend to be of similar age, this aggregation would likely not substantially distort the patterns of savings of individuals over the life-cycle. This would be so even if households are not unitary, because with respect to consumption-smoothing over the life cycle each individual in the household has similar objectives. However, a large proportion of households in many countries consist of adults of two generations. ${ }^{1}$ Aggregate household savings at a point in time thus reflect the joint behavior of individuals at very different stages of their lives for many households.

When aggregate households savings are plotted against the age of the household head in settings where inter-generational co-residence is prominent, one typically gets a U-shaped or flat pattern of savings by age (e.g., Hayashi (1986) for Japan; Deaton and Paxson (2000) for Thailand), rather than the inverted-U shape predicted by the classic life-cycle model when incomes rise with age for the young. Urban China, for example, has among the highest rates of co-residence in the world, with $50 \%$ of men aged 30 co-residing with their parents. Figure 1 provides the pattern of savings rates by age, from age 25 through 54, based on data on urban households in 15 provinces and 126 cities from the 2013 Chinese Household Income Project (CHIP 2013), which shows the U-shape. In contrast, the savings rates by age in the United States, from the US Consumer Expenditure Survey

\footnotetext{
${ }^{1}$ Inter-generational co-residence is a common feature of rural populations in most countries of the world, and is becoming more common in urban areas of developing countries. The 2005 World Values Survey provides the answer to the question whether a respondent resided with his or her parents for combined rural and urban populations for 52 countries. Among men aged 25-39 in China, 41\% reported they were living with their parents, but China only ranked $21^{\text {st }}$ on the list. India, with a co-residence rate of $78 \%$ for the same age group had the highest rate. Thailand and Taiwan have overall inter-generational co-residence rates higher than $60 \%$ in this age group. The rate in the United States for the same age group is $11 \%$.
} 
of 2013, exhibit the theory-conforming inverted U-shape, as seen in Figure 2. And, the deviation at young and old ages in savings rates from the individual life-cycle model and from the pattern observed in the United States is precisely where inter-generational co-residence rates are high in China relative to those in the United States, as shown in Figure $3 .^{2}$

The problem for the identification of individual savings patterns from household data is not only that household savings are an aggregate of individual savings, but also that headship is selective by age. Heads of households in multi-generational households are typically defined by the oldest male (e.g., the Census rule for Japan (Hayashi, 1997)) or the highest-earnings male. Among the young only those who are not co-residing with their parents then would be considered heads of households, and such young heads earn significantly more than their counterparts who remain in the parental home. This is shown in Figure 4, which compares, based on successive Urban Household Survey (UHS) data sets from 1988-2009 for 25-29 year old males, the ratio of the annual earnings of those who are (non co-resident) household heads to those of non heads. ${ }^{3}$ The figure also shows that the fraction in this age group who are heads (not living with parents) has declined as the ratio has increased - young headship has been increasingly selective in China. ${ }^{4}$

We use data from China because, as noted below, they allow us to overcome a number of barriers to the identification of the determinants of life-cycle savings and inter-generational coresidence. We use these data to identify in particular how housing prices affect co-residence decisions and distort life-cycle savings rates in a context in which such decisions are family-based. In so doing, we can test the hypothesis that the unusually high urban housing prices in China are a

\footnotetext{
${ }^{2} \mathrm{~A}$ respondent is defined as co-resident if he resides with a parent, parent-in-law or an adult child aged 25 and over. In both the US and China data sets, earnings of the young rise with age.

${ }^{3}$ Headship and co-residence of the young are essentially mutually exclusive. The 2005 Chinese mini census data indicate that less than 5\% of men aged $25-45$ and residing with parents are considered household heads. Thus, almost all of young heads live without their parents and have higher earnings than young non-heads. There are six provinces (including the Beijing municipality) represented in this UHS data set. They are broadly representative of China's rich regional variation, namely, Beijing, Liaoning, Zhejiang, Sichuan, Guangdong and Shaanxi. Beijing is a rapidly growing municipality in the north; Guangdong and Zhejiang are dynamic high-growth provinces in China's south coastal region; Liaoning is a heavy industrial province in the northeast; Sichuan and Shaanxi are relatively less developed provinces located in the southwest and northwest, respectively. The same six-provinces data have been used in a number of studies (e.g. Zhang et al., 2005; Han et al., 2012).

${ }^{4}$ It is clear that a solution to the problem of household aggregation is not to test the life-cycle model on data from households that contain only one generation of adults. First, in the cross-section, because of headship (coresidence) selectivity by age, the earnings of young heads may not be lower than the earnings of older heads, since at older ages, as seen in Figure 3, headship is less selective, so that savings rates may be flat by age in this selective subsample. Second, restricting tests of life-cycle savings to panel data on individuals who were initially and continue living alone, while more suitable to the application of the classic model, would at best confirm the model for only a small and non-representative sample of the population.
} 
major factor explaining both the relatively high rates of young savings and co-residence, with the choice of inter-generational co-residence playing a key role in augmenting the savings rates of the young..$^{5}$ And we can use our estimates to calculate by how much the savings and co-residence rates of the young in China would decline relative to those of middle-aged households if housing prices in China were at levels similar to those in the United States.

Housing prices in China are unusually high and have been so for along time. Wu et al. (2012) find that the average ratio of the price of housing to household income in eight major Chinese urban housing markets in 2002 ranged from 7 to 12 (their Figure 12). More recently, Fang et al. (2015) computed housing prices for 120 cities in China. Their data indicate that in 2013 the average ratio of the housing price to per-capita disposable income was 7 in the top four most populous (Tier-1) cities (Beijing, Shanghai, Gunagzhou, and Shenzhen) for middle-income borrower, while housing prices were on average 6 (middle-income) times higher than per-capita disposable income in the 31 secondtier cities for which they compiled data. These ratios are similar to that for Japan during its housing boom, 8.9 (Noguchi, 1994), when the U-shaped savings rate patterns were documented by Hayashi. In contrast, Richards (2008) reports that a similarly-calculated ratio for the United States and the United Kingdom in 2002 was around 3 (their Figure 7) and, as reported in Cheng et al. (2014), the housing price-to-income ratio in the United States, even during the later housing boom period, was also 3. Home ownership rates among persons aged 45 and older are also significantly higher in China compared to those in the United States - 88\% in urban China (2011 CHARLS) versus 75\% (2013) in the United States (US Census Bureau, Current Population Surveys, 2018).

We are able to overcome the limitations of previous studies of the determinants of life-cycle savings and co-residence using both unique data and unique features of the Chinese economy. These new data allow us to both quantify the causal effect of housing prices on living arrangements and life-cycle savings and to illuminate the roles of household aggregation and co-residence choice in masking the true patterns of individual savings rates over the life cycle. There are three principal barriers to identifying empirically how and by what mechanisms housing prices affect the patterns of savings over the life-cycle: (i) the lack of information on the savings of couples or individuals that is uncensored by inter-generational co-residence, (ii) lack of information on the incomes of all family members regardless of whether they co-reside, and (iii) the endogeneity of housing prices. With respect to the latter, where co-residence happens to be more desirable, due, say, to enhanced family

\footnotetext{
${ }^{5}$ Wei and Zhang (2011) argue that high housing costs are one of the mechanisms through which marital competition results in higher savings. As our model makes clear, we are not claiming that the cost of housing is the only determinant of high young co-residence or savings rates.
} 
support values, the demand for housing units would be lower, and thus the price of housing possibly lower - the housing price is endogenous in equilibrium. Housing supply may also respond endogenously to housing demand.

To overcome the first barrier, the absence of savings information for individuals or couples who co-reside with parents, we use data we have collected on twins and non-twins and their siblings in five Chinese cities, the Chinese Twins Survey (CTS) and the Chinese Non-Twins Survey (CNTS). ${ }^{6}$ A key feature of these data is that, because the survey design is based on individuals, there is information on individual (or couple) savings, regardless of living arrangements. Savings are not aggregated at the household level. As seen in Figures 5 and 6, these data display the same patterns with respect to co-residence as in the CHIP 2013 but show that individual savings of the young, aged 25-34 and uncensored by co-residence, are higher than those of the middle aged. ${ }^{7}$ Thus, co-residence is not masking the high savings rates of the young displayed in Figure 1. However, the high household savings rates of older heads, also seen in Figure 1, appear to be solely the result of the fact that many of the old are co-residing with high-saving young, since the individual savings of the old decline with age, as expected in canonical life-cycle models, as seen in Figure 6. Thus, the deviation from the canonical individual life-cycle savings models appears to be strictly among the young.

The cost of housing is not the only determinant of living arrangements or savings among family members. To test the hypothesis that co-residence and savings are linked and affected by the price of housing it is necessary to employ a family-based framework in which co-residence is a choice jointly made by two generations of adult family member. This requires data that describe at a minimum the earnings of all siblings or adult children as well as parents that are not censored by any family members departing the household. Almost all data sets, which are household-based, provide information only on family members who co-reside in the sampled household; such household data therefore cannot be used to determine the choice of who resides with whom. However, the data based on the survey of twins contain information on the earnings of both of the twins as well as

\footnotetext{
${ }^{6}$ There are 4,683 respondents in the CTS and 1,665 in the NCTS. The five cities represented are Chengdu, Chongqing, Harbin, Hefei, and Wuhan. These data are described in more detail below in Section 5.

${ }^{7}$ The savings question in the CTS and CNTS was "Last year, how much was the increase in your assets (including cash, bank deposit, various financial securities etc.)?" This is different from the method by which savings is calculated in the UHS, which subtracts total household consumption from total household disposable income. We compared the savings measures from the 2002 UHS and the savings measures from the CTS and CNTS for nuclear (non co-resident) households, and thus not subject to the aggregation problem in the UHS, and found that the savings rates and levels were comparable.
} 
their siblings, information on parents and information on intra-family transfers for each twin, regardless of co-residence, enabling the application of a family-based framework. A deficiency of the twins data set, however, is that it contains no information on housing prices.

A second major data set that we use is the 2013 CHIP. This data set is one of the few, in addition to our twins and non-twins data, to provide information on the earnings of all of the adult children of household heads regardless of their co-residence, as well as information on the parents of all adult respondents regardless of co-residence. In addition, the CHIP 2013 data provide information on housing values as well as housing characteristics. The latter two sets of variables enable us to the construct quality-adjusted per-area housing prices for each of the 126 cities represented in the CHIP 2013.

To identify the causal effect of variation in housing prices when such prices are endogenously-determined we exploit the fact that, unlike in pure market economies, in China the supply of housing is strictly controlled by the government through its provision of land released for developers. Recently, data have become available on a key element in the formula the government uses to determine the amount of land released for residential housing, namely the size of the rural population re-categorized as urban (Gan et al., 2019). This re-classified population adds to the total urban population count that informs the land allocation decision, but unlike the population of true migrants, a change in this population component does not increase housing demand, since the newly-defined urban residents already have housing. However, the Chinese government formula increases housing supply based on total urban population growth, regardless of the reasons for the increase. Thus, the re-classified urban population size affects the amount of land available for the supply of residential housing (positively) but not housing demand. It can thus serve as an instrument for the price of housing in identifying the causal effects of housing prices on both co-residence and savings rates among the native urban residents, when living arrangement choices and macro economic shocks jointly affect the demand for housing.

There are many studies in the urban economics literature finding that housing prices are correlated with co-residence or household formation (e.g., Ermisch, 1999; Lee and Painter, 2013), but none has taken into account the feedback effects of co-residence choices on housing prices. And, no studies have tested whether variation in housing prices affect savings. While we know of no study that has attempted to implement a strategy that enables the identification of housing price effects when housing prices are endogenously-determined, some researchers have not been unaware of the problems that household aggregation poses for assessing the classic life-cycle savings model. 
Deaton and Paxson (2000) propose and implement a method for identifying individual savings behavior from household data by projection methods, using information on the individual earnings and age structures of the members of households. This method, as the authors point out, relies on the assumption that co-residence per se has no effect on life-cycle savings, so that household coresidence simply "veils" individual savings behavior. This is an untestable assumption if all data on savings comes from aggregate household data and is unlikely to hold if there are scale economies in co-residence, which in part arise because housing is a household public good. The question thus is who benefits from such economies.

There is empirical evidence that co-residence of young and old represents a subsidy to the consumption of the young. Rosenzweig and Wolpin (1993) examine parental assistance to young adult children in the form of both shared residence and financial transfers in the United States, finding that shared residence is an important component of young-age support that varies inversely with public assistance. A number of studies have exploited pension reforms to quantify the causal effects of the income of the old on co-residence. In particular, Edmonds et al. (2005) and Manacorda and Moretti (2006) examine pension reforms in South Africa and Italy, respectively, to show that changes in the incomes of the old affect the likelihood of co-residence with their adult children. Manacorda and Moretti explain this phenomenon using a model in which parents bribe their children to live with them, thereby subsidizing their consumption. ${ }^{8}$

None of these studies of co-residence has linked co-residence to savings. Their findings, however, not only imply that co-residence would affect the savings of the young, but also suggest the inadequacy of using an individualistic framework for studying savings. If co-residence affects the consumption costs of the young, and represents a joint decision of multiple-generation family members, then it is necessary to study savings and co-residence jointly from a family perspective. The individual life-cycle model may simply be the wrong model to describe savings behavior in a world in which co-residence characterizes a major fraction of the population and is a potential mechanism for sustaining savings for the young. Moreover, as noted, the limitations of most household-based data sets limit the ability to fully test models of co-residence.?

\footnotetext{
${ }^{8}$ Costa (1997) exploited changes in Union army pensions to show that in the United States prior to 1940, rising own income was a major factor in reducing co-residence, but lower housing costs after that period reduced the importance of income.

${ }^{9}$ The pension reform studies provide a relatively clean estimate of how changes in the older generation's income affects their co-residence, but the household data used cannot examine how the incomes of the young affect co-residence because the incomes of the young adults in a multi-generational family are only available in their data if they co-reside with the older family member. Hayashi (1997) models and studies co-residence in Japan, but as he discusses the
} 
The one important exception to the literature on savings and co-residence is Kaplan (2012). Kaplan formulates a dynamic stochastic model that incorporates both endogenous savings by the very young and their endogenous co-residence in a family context. Moreover, Kaplan estimates the model using one of the few data sets in the world that has both individual wealth information as well as information on parents and adult children, the 1997 National Longitudinal Survey of Youth (NLSY97) panel. From his structural estimates he is able to assess counter-factuals including the savings effects from shutting down co-residence or the option of returning home. The focus of Kaplan's analysis, however, is how savings and co-residence mitigate the effects of fluctuating incomes for very young, poor men, specifically men aged 17-22 who are not in high school and never attend college. ${ }^{10}$ Employment risk is thus the key driver of savings ("precautionary" motive). Co-residence affects young savings due to the young enjoying free rent from parents and sharing in the household public good, but co-residence with parents also acts as a substitute for savings in providing insurance against job or income loss.

The focus on precautionary savings related to employment risk leads to an empirical analysis in Kaplan (2012) that estimates how fluctuations in incomes or employment affect co-residence for these very young men using the NLS97 panel. However, when individual fixed effects are used, the coefficients on income or employment, the key variables driving residence choice, are statistically insignificant. Moreover, in further empirical analysis using more representative CPS data sets covering the period 1979-2010, when controls for housing costs are included, for the age group 1634, the coefficients for the employment rate and hours worked are cut by two thirds and become statistically insignificant using the quarterly data. This result is not surprising - housing costs affect co-residence in the model, but in the aggregate employment shocks and housing (rent) costs are likely to co-move. Indeed, in general-equilibrium, changes in co-residence rates will affect the price of housing (demand effects). This co-variation is not taken into account in estimating the partialequilibrium structural model. ${ }^{11}$

We employ a simple family-savings framework to fix ideas about data requirements for studying the interactions among housing prices, co-residence and savings and to generate a coherent

data he could work with lacked important information for such an inquiry, such as the characteristics, especially the incomes, of both parents and children when family members live apart.

\footnotetext{
${ }^{10}$ This sub-sample selected with the low-schooling ceiling represents only $43 \%$ of all males aged $17-22$ in the NLSY97, which itself over-samples poorer populations.

${ }^{11}$ In estimating the structural model, shocks to employment are assumed to be orthogonal to housing prices (and to taste shocks for co-residence).
} 
set of hypotheses. The model incorporates some of the major features of Kaplan's model. First, coresidence represents support by the old of the young, as is also assumed by Manacorda and Moretti (2006). This is relevant to China - among households in which 25-34 year-olds live with their parents, less than $1.7 \%$ of the homes are owned by the young (CHIP 2002), with $88 \%$ of urban residents aged 45 and older owning their home (CHARLS, 2011). ${ }^{12}$ Second, we find evidence that co-residing young do not pay (full) rent or any significant consumption costs (home meals) as in coresident households individual savings by parents are lower than in households in which the young do not reside. Thus, co-residence permits higher saving rates by the young, accompanied by lower savings rates of the old.

Our framework deviates from Kaplan's model in three major dimensions. First we assume away employment uncertainty. We do this because for the principal age group we examine, respondents aged 25-34 and for older adults, unemployment rates are extremely low in China. This is seen in Figure 7 from the CHIP2013 - while unemployment rates average 15\% for the age/education group 17-22 studied by Kaplan (based on US data), they average less than 3\% for those (high-savers) aged 25-34 in China. Kaplan's model highlighting employment risk and precautionary savings appears as relevant for the very young poor in China as for those in the United States, but not especially so for those aged above 24 in China that we focus on here and where the deviations from the canonical savings model are greatest. ${ }^{13}$

Second, to simplify the model yet retain the key elements relevant for studying savings in a family life-cycle context, we assume the family jointly makes Pareto-efficient decisions, so there is no game-theoretic dimension to the model. Third, we also assume away credit constraints, retaining the spirit of the original life-cycle savings framework and isolating the role of housing costs in creating deviations from the original model predictions. This latter is obviously not realistic for the young but is not unique to China. Moreover, unlike for housing prices, the absence of variation in credit constraints in the data sets we use precludes identifying empirically the role of credit restrictions.

In section 2 we set out the illustrative family-based theoretical framework incorporating

\footnotetext{
${ }^{12}$ In contemporary urban China, many of the old acquired their homes during housing reforms at highly subsidized rates (Wang, 2011). The current young, however, face unsubsidized and high housing costs, and would have to wait many years to inherit their parent's home given the approximate 25-year age gap between parents and children. Many of the current urban old in China also have generous pensions, at replacement rates of up to $80 \%$. China is not unique in this respect. In many countries of the world co-residence of parents and adult children in households headed by the old in urban areas is more likely reflective of support by the old of the young (Ruggles and Heggeness, 2008).

${ }^{13}$ Indeed, in Kaplan's model employment risk is assumed to disappear after age 25, as does the possibility of coresidence. In our simplified model we also have a terminal period in which co-residence is not an option, but it is after age 34 .
} 
inter-generational co-residence and housing costs, building on the classic life-cycle model of savings, that motivates the empirical analysis. The model yields predictions for the effects of the housing price on co-residence and on savings for those co-residing and those not. A key prediction is that the individual savings rates of the young will be higher when co-residing. In section 3, we describe the data sets and the construction of the quality-adjusted housing price data that we use in our subsequent empirical applications, and our identification strategy for estimating the causal effects of housing prices on saving rates and co-residence. Section 4 reports IV estimates using the CHIP 2013 that quantify the effects of quality-adjusted housing prices on the household incomes and household savings rates of young heads aged 25-34 and heads across the wider age range 25-64. We find that, as expected given the housing supply formula, that population growth increases housing prices while, given total urban population size, the larger the re-classified population component of the total, the lower are housing prices. Our IV results are consistent with the predictions of the model - higher housing prices increase young head savings rates and the household incomes of the young heads. Moreover, once we control for household income, the effect of housing prices on young savings rates disappears completely, as is also consistent with the model. The elevated savings rates of young heads thus appear to be solely due to selection.

In section 4, we also assess directly how housing prices and the earnings of the set of adult children affect the co-residence of heads aged 45-64 with their adult children. The results are again consistent with headship selectivity: using our instruments, we find that (a) higher housing prices increase the probability of co-residence, with the OLS estimates underestimating the effect of housing prices on co-residence by $44 \%$ and (b) higher average earnings of the adult children lower co-residence rates. As a robustness check, we combine the 2002 and 2013 CHIP data sets, both of which enable the estimation of quality-adjusted city-level housing prices, to estimate the effect of housing price variation on the co-residence of the young aged 25-34 using IV but also including city fixed effects. The results are similar. Finally, in this section, we test whether the earnings of adult children affect the household-level savings of heads aged 45-64. The estimates indicate rejection of the null, suggesting that aggregate household savings are determined in a family not just an individual or household context.

Using our data set on twins in section 5, we estimate using instrumental variables the effect of co-residence on the individual or couple savings rates net of own income using the average income of siblings as the instrument. We find that co-residence doubles savings rates. We also check the exclusion restriction that sibling income has no direct effect on own consumption by estimating the 
effect of sibling income on out-transfers. While own income affects expenditures on transfers, sibling income has no economically or statistically significant effect. We then estimate the effects of inter-generational co-residence on the individual/couple savings of respondents aged 45-60. Using average adult child income as an instrument for co-residence, for this age group, unlike for the young, we find no effect of co-residence on savings rates. Evidently, the savings from intergenerational co-residence are enjoyed solely by the young. Thus, the cost of higher housing prices is born by the parents of the young. Finally, our IV point estimates of the effects of the housing price on the co-residence of the young with their parents and of the effect of co-residence on their savings rate imply that if the price of housing were like that in the United States in terms of affordability (price/income ratio), the savings rate of the young in China would be $21 \%$ lower.

2. An Illustrative Family Model of Savings and Co-Residence

A. Co-residence and optimal savings. The selectivity of headship observed in Figure 3 is consistent with co-residence being the choice of lower-income young. But co-residence also reflects the decisions of parents, whose income is correlated with those of their adult children, and both coresidence and the costs of housing may have direct effects on savings as well. To parsimoniously illustrate the implications - both for data and for the effects on life-cycle path of savings of variation in housing prices - from embedding savings in a model of family behavior, we construct a simple multi-period two-generation model. Parents and their adult children jointly determine their optimal consumption paths and whether to share the parents' residence when the adult children are young. ${ }^{14}$

To highlight the multiple links between savings and co-residence while retaining parsimony we make a number of simplifying assumptions. First, we assume that parents and children consume a fixed amount of housing services $h$ and that parents and children face an exogenously-determined housing services rental price $\pi$. Second, we assume that credit and housing markets are perfect. ${ }^{15}$ The assumption of perfect credit markets is in the spirit of the benchmark life-cycle model of savings and allows us to identify how the incorporation of co-residence selection and housing costs leads to departures from the classic model. Third, we also assume that labor markets are perfect, unlike in Kaplan (2012). There is thus no unemployment risk, consistent with the data for the age group over 24 that is our focus. As a consequence, there is no precautionary savings motive. We also initially

\footnotetext{
${ }^{14}$ We assume a cooperative model. We obtain the same qualitative predictions with respect to child and parent income effects on co-residence as in the non-cooperative model of Manacorda and Moretti (2006).

${ }^{15}$ Restrictions on borrowing and down-payment requirements, as modeled by Hayashi, et al. (1988), would reinforce the relationships we obtain in the model. There is no variation in our data to identify the role of credit market constraints.
} 
assume that the children are identical and examine the behavior of the representative child. We then consider how differences among children within the family affect their respective savings and coresidence decisions.

There are two generations, parents and children ( $k=$ children, $p=$ parents $)$, and three time periods in which children and parents overlap. In the first period, children are born and raised by parents who jointly reside. We ignore decisions (fertility, parents savings) in this period. In period two, children are "young" adults, parents are middle-aged and both participate in the labor market. Parents own their home, the asset value of which is $\pi h / \delta$, where $\delta$ is the discount rate. All of the wealth from housing is consumed by the parents. ${ }^{16}$ The children and the parents may choose to coreside in this period. Parents provide free housing services $h$ for the children if they choose to coreside. Otherwise children pay $\pi$ per-unit of housing. Housing services are thus a household public good, but the utility of housing services is discounted if there is co-residence, and housing services are thus a decreasing function of the number of young $N$ for the young (privacy is valued). ${ }^{17}$ In period three, children must leave the original household if they co-resided in the second period and parents are retired, earning pension income $P$. There are thus two regimes in the model, a regime of co-residence in the second period with parents paying housing costs and a regime of non-coresidence in which adult children always live apart and pay housing costs $\pi h$ in periods two and three.

The non co-residence regime program is

$\max$

$$
U=U_{p}^{1}\left(C_{p}^{1}, h\right)+U_{p}^{2}\left(C_{p}^{2}, h\right)+U_{k}^{2}\left(C_{k}^{2}, h\right)+\delta U_{p}^{3}\left(C_{p}^{3}, h\right)+\delta U_{k}^{3}\left(C_{k}^{3}, h\right)
$$

subject to:

\footnotetext{
${ }^{16} \mathrm{We}$ are thus assuming that parental housing wealth is not bequeathed to the adult children. Financial instruments to convert housing wealth to income, such as reverse mortgages, have just become available in China. Hanewald et al. (2019) find based on survey data that the top priorities of the elderly for exploiting their housing wealth are to augment their pension income and to pay for their medical expenditures, not to provide bequests. It is easy to show that if children inherited the parental dwelling an increase in $\pi$, which would increase the value of the parental bequest and thus future young income, would decrease young savings. However, this effect is always dominated by the housing price channel highlighted in the model because the inheritance effect is both discounted and is inversely proportional to the number of siblings while the housing-cost effect of a change in $\pi$ is not.

${ }^{17}$ Sharing the parental home is the only mechanism in the model by which parents support adult children. We thus ignore direct financial transfers. In the CTS data, which provide information on goods and financial transfers between parents and adult children (and among siblings) regardless of living arrangements, net transfers from parents to children in the age group 25-24 are small. Less than half of parents provided any transfers in the year preceding the survey, and $90 \%$ of the net transfers when parents gave any transfers to the adult children aged 25-34 were less than 1,500 RMB (mean= 393 RMB.). Average disposable income for this age group is 16,500 RMB. Below, in section 5 we show that transfers to and from adult siblings are also negligible.
} 


$$
\begin{aligned}
& C_{p}^{1}+C_{p}^{2}+C_{p}^{3}=Y_{p}^{2}+\delta P+\pi \frac{h}{\delta} \\
& C_{k}^{2}+C_{k}^{3}+2 \pi h=E w(1+\delta)
\end{aligned}
$$

where the $C_{k}^{i}, C_{p}^{i}=$ consumption for each generation in each period $i$. Note that unlike in the model of co-residence in Hayashi (1997), parents and children do not pool income, though there is the option of inter-generational support in the form of shared housing. ${ }^{18}$ Constraint (3) reflects the fact that the children's earnings depend on their amount of skill $E$ and the market price of skill $w$.

Under the non-co-residence regime, the "young" savings function in period 2 is

$$
S_{k}^{2}=E w-C_{k}^{2}-\pi h .
$$

The co-residence regime program is

$\max$

$$
U=U_{p}^{1}\left(C_{p}^{1}, h\right)+U_{p}^{2}\left(C_{p}^{2}, h\right)+U_{k}^{2}\left(C_{k}^{2}, \delta(N) h\right)+\delta U_{p}^{3}\left(C_{p}^{3}, h\right)+\delta U_{k}^{3}\left(C_{k}^{3}, h\right)
$$

subject to

$$
\begin{gathered}
C_{p}^{1}+C_{p}^{2}+C_{p}^{3}=Y_{p}^{1}+\delta Y_{p}^{2}+P+\pi \frac{h}{\delta} \\
C_{k}^{2}+C_{k}^{3}+\pi h=E w(1+\delta) .
\end{gathered}
$$

and under the co-residence regime, the savings function in period 2 is

$$
S_{k}^{2}=E w-C_{k}^{2}
$$

The first implication of the model is that optimal "young" savings $\left(S^{2 *}{ }_{k, N C}\right.$ and $\left.S^{2 *}{ }_{k, C}\right)$ is higher under co-residence (indexed by subscript $C$ ) than under non co-residence $(N C)$, for the same lifetime income of the young:

Proposition 1: Savings are higher for the young under co-residence than under non-co-residence for the same lifetime income.

That is

$$
S_{k, N C}^{2 *}<S_{k, C}^{2 *}
$$

as

$$
C_{k, N C}^{2 *} \leq C_{k, C}^{2_{*}^{*}} \leq C_{k, N C}^{2_{*}^{*}}+\pi h \text { and } C_{k, N C}^{2_{*}^{*}}=C_{k, N C}^{3 *}, C_{k, C}^{2 *}<C_{k, C}^{3 *}
$$

Proof is in Appendix A.

B. Housing costs, co-residence and optimal savings. Which regime a child is in is a choice, so that the effects on savings cannot be understood without also considering how the change in the

\footnotetext{
${ }^{18}$ Altonji et al. (1992) reject the pooling model using U.S. data.
} 
housing services price or any other parameter in the model affects regime choice (co-residence). For changes in the cost of housing $\pi$, we get

\section{Proposition 2: An increase in housing costs increases co-residence.}

Proof: Defining optimized utility as $V^{\mathrm{C}}$ and $V^{\mathrm{NC}}$, respectively, in each regime, we have for the non-co-residence regime

$$
\frac{\partial V^{N C}}{\partial \pi}=\frac{\partial L}{\partial \pi}\left|\mathbf{C}_{N C}^{*}=-2 \lambda_{2} h\right| \mathbf{C}_{N C}^{*}=-2 U_{k 1}^{2} h\left|\mathbf{C}_{N C}^{*}=-2 U_{k 1}^{3} h\right| \mathbf{C}_{N C}^{*}<0
$$

where $\mathbf{C}_{N C}^{*}$ denotes the vector of the optimized consumption level for parents and kids within the non-co-residence regime. Similarly, for the co-residence regime

$$
\frac{\partial V^{C}}{\partial \pi}=\frac{\partial L}{\partial \pi}\left|\mathbf{C}_{C}^{*}=-\lambda_{2} h\right| \mathbf{C}_{C}^{*}=-U_{k 1}^{2} h\left|\mathbf{C}_{C}^{*}=-U_{k 1}^{3} h\right| \mathbf{C}_{C}^{*}<0
$$

where $\mathbf{C}_{C}^{*}$ denotes the vector of the optimized consumption level for parents and kids under the coresidence regime and $L$ is the relevant Lagrangian of the programming problem. An increase in the cost of housing decreases utility in both regimes, but as can be seen from (9) and (10) :

$$
\left|\frac{\partial V^{C}}{\partial \pi}\right|<\left|\frac{\partial V^{N C}}{\partial \pi}\right|
$$

Thus, for the family just indifferent between co-residence and non-co-residence, an increase in the cost of housing services leads to the choice of co-residence.

Given propositions 1 and 2, we can then obtain the effect of a housing price rise on agespecific savings. In this model with perfect capital markets, it is straightforward to show that a change in housing costs would have no effect on the age-structure of savings in the absence of coresidence, because for the non-co-resident children optimal consumption declines equally in all periods, by $h \pi$. However, for co-resident young adult children the higher housing cost increases savings, as the higher housing price in the third period lowers consumption in period 3 but not period two (the proof is in Appendix B). We then get

Proposition 3: Higher housing costs increase the young's savings when co-residence with parents is an option.

An increase in $\pi$ induces more young to co-reside in the parental home (Proposition 2), where savings are higher (Proposition 1), increases savings for the co-resident young, but has no effect on 
the non co-resident young. ${ }^{19}$

C. Young income, parental income, savings and co-residence. We can also show that increases in children's income, for given parental income, reduces co-residence:

Proposition 4: Higher-income young are less likely to co-reside with parents.

Proof: An increase in lifetime income, with no change in the temporal pattern of income, increases optimized utility $V$ in both regimes. But, because $\mathbf{C}_{k, N C}^{*} \leq \mathbf{C}_{k, C}^{*}$, the increase in optimized utility $V^{\mathrm{NC}}$ is larger than the increase in $V^{C}$ (details of proof in Appendix D).

Proposition 4 is consistent with the facts, presented above, that young non-co-resident males (heads) have higher earnings than their co-resident counterparts - co-residence is negatively selective in income. In addition, given (9) and (10), when there is an increase in the housing price, for the marginal child to remain indifferent between co-residing and not co-residing there must be an increase in her income. Thus,

Proposition 5: Increases in the housing price make the non co-resident young more positively selective with respect to income.

D. Parental income, inter-generational co-residence, and young savings. Our model delivers the result that an increase in parental income, whether pre-retirement or pension income, for given children's income, increases co-residence, consistent with the empirical findings of Edmonds et al. (2005) and Manacorda and Moretti (2006) for South Africa and Italy, respectively:

Proposition 6: An increase in parental pre-retirement or pension income increases inter-generational coresidence.

Proof: Higher parents' income at either period 1 or 2 always leads to higher parents' consumption levels, and hence higher $V^{C}$ and $V^{N C}$. It can be shown that

$$
\Delta D V=\Delta V^{N C}-\Delta V^{C}=U_{p 1}^{2}\left|\mathbf{C}_{p, N C}^{*}-\left[U_{p 1}^{2}+U_{k 2}^{2} h \delta_{2}\left(N, Y_{p}\right)\right]\right| \mathbf{C}_{p, k, C}^{*}=-U_{k 2}^{2} h \delta_{2}\left(N, Y_{p}\right) \mid \mathbf{C}_{k, C}^{*}<0,
$$

since $U_{p 1}^{2}\left|\mathbf{C}_{p, N C}^{*}=U_{p 1}^{2}\right| \mathbf{C}_{p, k, C}^{*}$,

where $\mathbf{C}_{p, k}^{*}$ indicates the vector of the optimal consumption goods by the parents and kids. ${ }^{20}$ Note that an increase in the price of housing also increases parent wealth, as homeowners. This is an additional mechanism by which an increase in the housing price increases co-residence and hence

\footnotetext{
${ }^{19}$ As noted, if the young expect to inherit the parental house, a rise in $\pi$ would lower young savings, but this effect is second order for households with more than one adult child and with discounting.

${ }^{20}$ Proof details are in Appendix C.
} 
savings by the young.

Another important implication of the model is that parents' pre-retirement or contemporaneous income also matters for the savings behavior of the young net of both the young's income and the parents' pension income, because of the option of co-residence. In the absence of co-residence there is no effect of parental pre-retirement income on the savings behavior of the young in the model. The sign of the effect of parent's income on savings by their young children in the presence of co-residence can also be informative about whether consumption and housing services are complements or substitutes:

Proposition 7: If housing services and consumption are substitutes an increase in parental preretirement income unambiguously increases the young's savings.

Proof: The disutility of shared housing services decreases with parental income, so for co-resident children consumption declines and savings increases (decreases) when housing services and consumption are substitutes (complements). For non-co-resident children, parent's income has no direct effect on their consumption. As Proposition 6 indicates, co-residence increases with parental income and savings is higher under co-residence (Proposition 1). Thus, savings for the young will increase regardless of residence regime when parental income is higher.

In sum, the model indicates that in a setting where housing costs are high and parents are home-owners and relatively well-off relative to their young children, co-residence is likely to be high and savings rates by the young also high, facilitated by shared residence. In this environment, an increase in the income of the young generation relative to the old decreases co-residence and thus has ambiguous effects on savings, which would otherwise rise in a regime without co-residence.

E. Heterogeneous children. In the model so far we have assumed that each child is identical. We now relax that assumption. We do this because most families across the world have multiple children and in the empirical section we will identify how changes in income affect savings and coresidence using variations across siblings (twins). The advantage of such estimates is that they eliminate the influence of unmeasured or imperfectly measured common family variables, for example, contemporaneous parental income, the incomes of all siblings, parental housing quality, or preferences, which the model indicates affect both decisions. The issue then is how the estimates correspond to the comparative statics for the representative child derived under the assumption of identical children. The key additional consideration is that changes in the earnings of one sibling can directly affect the behavior of the other sibling(s) because of co-residence and the privacy (crowding) externality. 
Consider a family with two initially identical children (siblings) that is just indifferent between the co-residence or non-co-residence of the children and parents. There is an exogenous increase in the earnings of one sibling, say sibling 1 . We want to know what happens to the difference in the utilities of co-residing and non-co-residing between the two siblings. That is we want to know what happens to the difference in the changes in the utilities associated with the residence regimes across the siblings

$$
\Delta D V=\left(\Delta V_{1}^{N C}-\Delta V_{1}^{C}\right)-\left(\Delta V_{2}^{N C}-\Delta V_{2}^{C}\right)
$$

when the lifetime earnings of sibling 1 increases.

From Proposition 4 we know that for sibling $1, \Delta V_{1}^{N C}-\Delta V_{1}^{C}>0$ when the lifetime earnings of sibling 1 increases and sibling 1 will move to non-co-residence if indifferent initially. For sibling 2 there is no change in the utility associated with non-co-residence. However, if sibling 1 chooses non-co-residence the gain from the co-residence regime increases for sibling 2 , even though sibling 2 experiences no income change, because there will be less crowding (more privacy) if she chooses to co-reside with parents. The effect of a rise in sibling 1's wages on the difference in coresidence choice utilities is thus

$$
\Delta D V=\left(\Delta V_{1}^{N C}-\Delta V_{1}^{C}\right)+\left(\Delta V_{2}^{C}\right)>0
$$

when the lifetime earnings of sibling 1 increases. The positive sign in (12) is the same sign as the effect of an own income change on sibling 1's own behavior. The cross-sibling effect reinforces the difference in residence choices by own income. Similarly, it can be easily shown that the sign of the effect of differences in earnings across siblings on the difference in their savings is the same as that of the comparative static for the representative child.

3. Data Sources and Identification Strategy for Estimating the Effects of the Price of Housing on Age-Specific Household Savings and Co-residence

A. Data on savings and co-residence. To assess whether and how increases in the price of housing affect savings for the young when co-residence is an option in the context of the multigeneration model we use three data sets. The first is the urban, non-migrant Chinese Housing and Income Project (CHIP) data for 2013, which describe 7,175 urban households in 126 cities in 15 provinces in China. This data set has a number of features relevant to the tasks. One is that there is information on the earnings, age and education of the adult children of household heads regardless of whether they are co-residing with the head. Thus it is possible to re-construct complete families using both the household rosters and the modules on non co-resident children to examine the family co-residence decision consistent with the family model. However, like almost data sets, the 2013 
CHIP provides total savings only at the household level. Thus, we can only estimate the effect of the housing price on the savings of the non-co-resident adult children. The model predicts that, net of income, the effect of the housing price should not be statistically significantly different from zero.

The 2013 CHIP also provides a housing module, which contains respondent assessments of the market and rental values of their domiciles along with information on the characteristics of the housing unit, including "useable area," the domicile's year of construction, location of the domicile within the city (center or not), and dummy variables characterizing the kitchen location, drinking water and washing water sources, types of sanitation facilities, types of heating facilities and fuel used for heating and cooking. From these data we can compute the city-specific price per area adjusted for the quality of the housing as indicated by its characteristics by regressing the household-specific per-area price on the set of quality characteristics of the domicile and a set of dummy variables for each city. The coefficients on the city-specific dummy variables reflect the variation in the city-level per-area price of housing net of housing quality characteristics.

The second data set we use is the 2002 CHIP. Like the 2013 CHIP, the 2002 CHIP has detailed information on the market value of owned housing and the market rental rate, as estimated by respondents, along with a comparable set of housing characteristics for 6,835 urban households in 77 cities. Thus it is also possible to construct city-specific, quality-adjusted housing prices for these cities for 2002. The 2002 CHIP, unlike the 2013 CHIP, however, does not provide information for adult children not co-residing with the household head.

B. Data on the determinants of housing supply and our identification strategy. The third data set we use enables us to implement an identification strategy to deal with the endogeneity of housing prices when families can choose to co-reside. Exogenous changes in co-residence reduce the demand for housing and thus the market equilibrium housing price, and, as the model indicates, exogenous changes in the housing price affect the co-residence choice. Thus the association between the market price of housing, co-residence and savings does not identify the causal effect of the housing price. What is needed are variables that shift the supply of housing that are independent of housing demand.

In modern China, the government determines the amount of land that can be devoted to residential and industrial uses in communities. Each year additional land is made available according to a formula that is mainly based on the total change in the urban population. If population change is the major determinant of increased housing demand, using population growth as an instrument for housing supply would be invalid. However, as shown in Chen and Song (2014) and Gan et al. 
(2019), population growth in any city has three components: indigenous change due to births and deaths, net rural-urban migration, and the expansion of urban areas through a re-classification of rural areas. The latter urbanized population component, which made up $40 \%$ of the growth in the urban population in the years 2000-2010 (Chen and Song, 2014) and a third of growth from 20112015 (Gan et al., 2019), consists of households who already own their domicile. ${ }^{21}$ Thus, urban population growth due to re-classification has no effect on the demand for housing, unless these formerly rural populations have unusually high future levels of income growth.

Gan et al. (2019) have assembled a data set consisting of the re-classified urban populations at the prefecture level by year over the period 2011-2015. They show that governmentally-determined residential land supply increases are as strongly related to "natural" urban population growth as they are to urban population changes due to re-classification. They also show that re-classified rural communities are no different from other rural communities in infrastructure or levels of economic activities at the time of re-classification. Re-classification is also not predictive of future income growth. Thus, the size of the re-classified urban population is a shifter of housing supply in a city due to the governmental formula, as shown in Gan et al. (2019), but is not a determinant of housing demand. We have matched the data put together by Gan et al. (2019) on the components of urban population growth aggregated at the city level to the cities in the 2013 CHIP. Of the 126 CHIP cities, we have matches for 96.

4. Specifications and Estimates: Household Savings and Co-Residence.

A. Household savings rates of young household heads. Neither CHIP data set, as noted, contains information on savings at the individual or couple level. We will first estimate the effects of the housing price on the savings rate and incomes of "young" household heads aged 25-34, where we see the high relative savings rate. These households consist mainly of the adult children in the family who have chosen not to co-reside with their parents, and thus the effect of the housing price on their savings reflects the selectivity of co-residence choice, as well as the effect on savings (if any) conditional on the co-residence decision. We will also test if the effect of the housing price on the savings of heads of households differs by head's age.

The specifications we estimate, using 2SLS, are:

$$
z_{d i \mathrm{j}}=\beta_{d} \pi_{\mathrm{j}}+\varepsilon_{\mathrm{kij}}
$$

\footnotetext{
${ }^{21}$ In CHIP 2013, 27\% of the urban, non-migrant sample respondents had in the past changed their Hukou from rural to urban.
} 
where $\tau_{\text {dij }}=$ the savings rate for household $i$ in city $j(d=s)$ or the income of the household $(d=Y), \pi_{\mathrm{j}}=$ the city-level quality-adjusted price of housing, and $\varepsilon_{\mathrm{kij}}$ is the error term. The model predicts that the savings rates of non co-resident children who head their own household, conditional on income, are not affected by changes in the price of housing so that $\beta_{s}, \beta_{Y}>0$ in (13) due solely to selection. This is because only the highest-income children do not co-reside with parents when the price of housing is very high, and savings rates rise with income. Conditional on income, the savings rate of the young heads should be unrelated to the housing price.

The first-stage equation is

$$
\pi_{\mathrm{j}}=\gamma_{1} p o p_{\mathrm{j}}+\gamma_{2} r_{\mathrm{j}}+\mathrm{e}_{\mathrm{j}}
$$

where $p o p_{\mathrm{j}}=$ size of the urban population in city $j$ and $r c_{\mathrm{j}}=$ re-classified urban population component of the total urban population. We expect that $\gamma_{1}>0$, as increases in the population, net of the reclassified populations, increase the demand for housing. On the other hand, $\gamma_{2}<0$, as an increase in the re-classified population, net of the total population, increases housing supply without a commensurate increase in housing demand, as noted.

Columns one of Table 1 reports the IV estimate of equation (13) for the savings rate of household heads aged 25-34 using CHIP 2013, with standard errors clustered at the city level. The coefficient on the housing price is positive and significant - young savings rates (of heads) are higher where housing prices are also higher. The point estimate indicates that a one standard deviation decrease in the price of housing would lower the savings rate of young heads by 2.6 percentage points, or by $7 \%$. Column two of Table 2 reports the first-stage estimates. As expected, the price of housing is higher the higher the total urban population, but the price is lower the larger the reclassified component of the urban population. The diagnostic statistics in Tables 1 and 2 indicate that the estimate of the housing price on the savings rate is well-identified.

The estimated coefficient for the housing price in the specification in which the income of the young head is the dependent variable, in column two of Table 1, is consistent with young headship being positively selective with respect to income - the coefficient statistically significant and positive, and appears by the diagnostic statistics to be also well-identified. The point estimate indicates that a one standard deviation increase in the housing price increases the mean income of young heads by $25 \%$. And in column three we see that, controlling for head's income, which has a statistically significant positive effect on the saving rate, there is no significant effect of the housing price on young head savings. As indicated by the model, changes in the housing price have no effect on the saving rate of non co-resident children. All of the observed excess savings rate of young heads 
appears to be due to selection (Proposition 5).

Of course, it may be that the saving rates and incomes of older heads are also positively affected by increases in the housing price in contradiction of the model. To see that it is only the young heads' saving rates that are affected positively we estimate the saving rate and income equations for households heads across the extended age range 25-64, allowing the coefficient on the housing price to differ by age by including an interaction term of head's age and the housing price. The IV estimates of the interactive specification for the saving rate and head's income are reported in columns four and six respectively. As expected, the positive housing price on both the saving rate and income is confined to the younger heads. The point estimates indicate that the housing price effect turns from positive to negative at head's age 51 for the saving rate and declines steadily over the full age range for income. The negative interaction coefficients are robust to the inclusion of city fixed effects, as seen in columns five and seven.

The interaction specification imposes linearity on the price effects. We also used the locallyweighted functional coefficient model estimator (LWFCM) of Cai et al. (2006) to obtain nonparametric estimates of the housing price effect by age. The estimates of the housing price coefficients by head's age in the saving rate equation, along with their $95 \%$ confidence bounds, are displayed in Figure 8. As can be seen, the positive housing price effect on the head's saving rate is only statistically significant for the youngest heads. The evidence of the positive selectivity of headship with respect to the housing price for the young is seen even more clearly in Figure 9, where the LWFCM estimates of the housing price coefficients by age in the income equation are displayed both for heads and for all respondents. While the housing price coefficient for income declines steeply by age for heads of households, the coefficient remains relatively flat across the full age range for all persons.

B. Co-Residence. We now estimate the effect of the housing price on co-residence using the re-constituted family data from the CHIP 2013. In particular we estimate using our IV strategy for the housing price the determinants of co-residence for household heads aged 45-64 with any adult children. In accord with the two-generation model we estimate the effects of the housing price, head's income, and the average incomes of all adult children on the probability that at least one of the children is co-residing with their household head father.

The specification is:

$$
c_{i j}=\alpha_{1} \pi_{j}+\alpha_{2} Y_{p i j}+\alpha_{3} Y_{k i j}+Z_{i j} \alpha_{k}+\xi_{i j}
$$

where $c_{i j}=1$ if the head aged 45-64 in family $i$ in city $j$ co-resides with any of his adult children, $\pi_{j}=$ 
the quality-adjusted housing price in city $j, Y_{p i j}=$ income of the head, $Y_{k i j}=$ average income of all of the adult children of the head, and $\boldsymbol{Z}_{i j}$ is a vector of control variables, including the average schooling and age of the adult children and the proportion of the children who are male, an indicator for whether the head is retired, and the head's schooling. The model predicts that $\alpha_{1}, \alpha_{2}>0$, while $\alpha_{3}<0$.

Column one of Table 3 reports the OLS estimates of (15). All of the key coefficient signs conform to the model - co-residence is more likely the higher the price of housing and the higher the head's income but is less likely the higher is the average incomes of the adult offspring of the head, with only the head's income coefficient not achieving statistical significance. These results are consistent with the selectivity interpretation of the positive effect of the housing price on the saving rates and incomes of young heads, who have chosen to split-off from their origin families.

The second column of Table 3 reports the IV estimates, with the excluded instruments predicting the housing price including the change in the re-classified urban population between 2012 and 2013, the total city population change between 2011 and 2013, and the city population size in 2013. ${ }^{22}$ The diagnostic statistics again indicate that the housing price effect is well-identified. The IV point estimate of the housing price is $44 \%$ larger than the OLS estimate, consistent with positive shocks to co-residence lowering the price of housing, although we cannot rule out that at least some of the downward bias is due to measurement error. All other coefficient values are similar in magnitudes and levels of statistical significance across the two columns. The IV point estimate indicates that a one standard deviation increase in the quality-adjusted housing price increases the probability of co-residence of older heads and their adult children by $14 \%$.

While use of the instruments to predict the city-specific housing price should in principle eliminate any bias due to the omission of city-specific omitted variables, to assess the robustness of the estimated housing price effect we merge the 2013 and 2002 CHIP data sets by city. This enables us to include a city fixed effect in the specification. The number of overlap cities, inclusive of the availability of the components of the city-specific urbanization population changes, is 41 . A limitation of the merged data set, however, is that the 2002 CHIP does not contain any information on the adult children of heads who do not co-reside. We thus cannot estimate (15) for older heads. We instead estimate the determinants of the probability of co-residence for the young, for respondents aged 25-34. A shortcoming is that we do not know the income of the fathers of the young adults, we only know father's education, and we do not have information on siblings. Nevertheless, we can

\footnotetext{
${ }^{22}$ The first-stage results are available from the authors upon request.
} 
check if our results for young earnings and the housing price on co-residence are robust to the inclusion of city fixed-effects.

Another potential determinant of co-residence for the young is the ratio of males to females in the cities. Wei and Zhang (2011), as noted, found that savings rates were correlated with sex ratios relevant to marriage markets using the same 2002 CHIP survey data. If co-residence is a means for parents to help children save, then we should expect that, based on their findings, where the sex-ratio is higher, co-residence should also be more prevalent. We computed the ratios of males to females in the 20-29 age range for each city based on data from the two CHIP surveys.

Column one of Table 4 reports the city fixed-effects estimates of the effects of the qualityadjusted housing price, father's schooling and own income on the probability of inter-generational co-residence for respondents aged 25-34. The results again conform to those in Table 3 and to the model predictions: co-residence is higher the higher the housing price, higher-income young are less likely to co-reside with parents, but co-residence is more likely if the father is more educated. Consistent with Wei and Zhang's hypothesis and with co-residence being used to raise savings as in our model, where there was a relative shortage of females (the male sex ratio is higher), co-residence rates of males are also higher. However, net of the sex ratio, co-residence and the city-level quality-adjusted per-area housing price are still positively and statistically significantly related.

The second column of Table 4 displays the IV and city fixed-effects estimates. The only significant change is that, as expected, the coefficient on the housing price increases, in this case by more than $100 \%$. The housing price point estimate indicates that a one standard deviation increase in the quality-adjusted price of housing would double the probability that a 25-34 year-old resides with her parents.

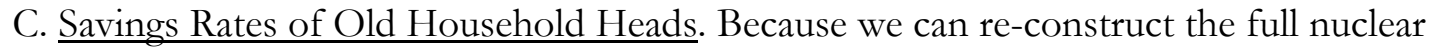
family for older heads and their adult children regardless of residence location from the CHIP 2013, we can also estimate the determinants of household-level savings for older heads consistent with the family savings model in which the incomes of the head and all the adult children are relevant because savings rates are affected by co-residence. That is, we can estimate equation (15) with the savings rate as the dependent variable. The first column of Table 5 reports the IV estimate of the housing price in a conventional specification of a household savings function, in which only the characteristics of head are included, for household heads aged 45-64 who have at least on adult child aged 25 and above. As expected, the household savings rate is greater the higher the income of the head. And, as was seen when estimating the effects of the price of housing on the household savings rate by the age of the 
head in Table 1, the housing price is not statistically significantly related to the household savings rate for the older heads.

In the second column of the table we report estimates from the specification in which we add the characteristics of the head's children - their mean income and schooling and the proportion with no job and male. The coefficients of the housing price and head's income are robust to the inclusion of these family variables, but the set of child variables are statistically significant at the .01 level. Most importantly, the coefficient for the average income of the adult children is negative and individually statistically significant. Given that, from Table 1, older heads are less likely to co-reside with their adult children when their income is high (co-residence income selectivity) and are more likely to coreside when the price of housing is high, the estimates of the effect of the average income of the adult children and of the housing price on the household savings rate imply both that co-residence increases the savings rate of the young but that the savings rate of the old declines with co-residence.

The null effect of a rise in the price of housing on aggregate savings in households headed by the old, despite such household being more likely to be inhabited by higher-saving young, is also consistent with inter-generational co-residence lowering the savings of the old. However, a rise in the price of housing increases the wealth of the home-owning older heads, which may decrease their savings even if living alone. If co-residence did not decrease the savings of the parents, we would expect that the effect of the price of housing on the aggregate savings rates of older household heads with adult children would be less negative (because of the aggregation with the young) than among households with older heads who are not co-residing with any adult children.

To estimate the housing price effect on household heads without co-residing children, and to minimize selectivity associated with the co-residence choice, we select a sample of heads with no adult children. The IV estimates of the saving rate for this group of heads is reported in the third column of Table 5. For this group, unaffected by co-residence, the effect of own income is again positive and statistically significant and the housing price coefficient is also negative, but it is statistically insignificant. The point estimates of the housing price effect for all older household heads who have adult children and those without any adult children are nearly identical, and the hypothesis that they are identical cannot be rejected at conventional significance levels. These results are agin consistent with the old subsidizing their co-residing adult children beyond providing them with rent-free co-residence.

5. Individual Savings Rates of Young and Old and Co-Residence

The preceding results indicate that a higher housing price does not increase the savings rates 
of either young or old household heads living by themselves. The elevated personal savings rates of the young, seen in Figure 6, thus appears to be due solely to personal or couple savings rates being higher only for co-resident young. Because higher housing prices increase inter-generational coresidence, the finding that higher housing prices do not increase the household savings rates of households headed by the old, some of which contain both old and young, as noted, suggests that the personal savings rates of the old are reduced when they co-reside with their adult children. This is consistent with the old directly subsidizing the consumption of the young who share the parental domicile. In this section we exploit the information on personal or couple savings and information on the complete set of respondent siblings in the Chinese Twins Survey (CTS) data (a) to test directly Proposition 1 that co-residence between young and old increases the personal savings rates of the young and (b) to test whether co-residence decreases the personal savings rate of the parents.

The CTS and the corresponding Chinese Non Twins Survey (CNTS) was carried out by the Urban Survey Unit (USU) of the National Bureau of Statistics (NBS) in June and July 2002 in Chengdu, Chongqing, Harbin, Hefei, and Wuhan. The local Statistical Bureaus identified same-sex twins aged between 18 and 65 using various channels, including colleagues, friends, relatives, newspaper advertising, neighborhood notices, neighborhood management committees, and household records from the local public security bureau. ${ }^{23}$ Overall, these sources permitted a roughly equal probability of contacting all of the twins in these cities, and thus the twins sample that was obtained is approximately representative. ${ }^{24}$ The UHS sampling frame was used to obtain a comparable sample of non-twins aged 25-60 in the same cities as the twins.

The survey frame was thus based on individuals and their families (spouses, siblings, children, parents), not households, although information was also obtained on household structure. There are 4,683 respondents in the CTS who completed the questionnaire, of which 2,990 are in matched twin pairs.

Our identification strategy here is based on the family model of co-residence in which any one sibling's choice of co-residence depends on the characteristics of both the parents and the

\footnotetext{
${ }^{23}$ All of the twins were born prior to the one-child policy in China and thus there were no incentives to misreport twinning as there was after the policy was put in place (Huang et al., 2016). Our estimates do not require in any case that the siblings be twins.

${ }^{24}$ These data have been used in a number of studies of China, including estimating the returns to Communist Party membership (Li et al., 2007), studying family behavior during the Chinese send-down movement (Li et al., 2010), and estimating the effects of birth weight on adult occupational choice, schooling and wages (Rosenzweig and Zhang, 2013).
} 
siblings as well as on the number of siblings. Thus, sibling income, sibling size (due to the crowding effects of co-residence), and parent characteristics are predictors of co-residence for any respondent. These variables are valid instruments for co-residence in a savings equation if, net of own income and co-residence, sibling and parent incomes do not directly affect savings. The key threat to identification is thus whether a change in the incomes of siblings or parental resources, net of own income, induces a respondent to remit transfers to the siblings or parents, which would alter her savings. ${ }^{25}$ We look at this issue next.

A. Estimates of the determinants of transfers to siblings and parents. The CTS data provide information on the amounts of transfers or gifts to each of the respondent's siblings and to parents. About half of respondents gave money to parents or siblings in the survey year, but the amounts are small. Fortyseven percent of respondents gave at least some money to parents, with the average transfer amount conditional on giving $650.7 \mathrm{RMB}$, which is less than $4 \%$ of total income. The corresponding figures for total transfers to all siblings is $52 \%$ and $429.9 \mathrm{RMB}(2.5 \%$ of total income). We can directly test if the parent and sibling variables that affect the choice of inter-generational co-residence also significantly affect transfers to siblings and parents, net of own income.

The transfer equation we estimate is the same as that for co-residence in (15) except that the dependent variable consists of transfers provided to either siblings or parents and we replace the parent income variable by variables indicating whether the mother or father has a skill occupation because the CTS does not contain parental income information. ${ }^{26}$ We also take advantage of the information in the CTS on the reports by twins of their counterpart twin's earnings, using these reports as instruments for own income, the largest component of which is earnings (87.4\%). This should reduce bias from measurement error in earnings, which will be particularly important when we use the savings rate as the dependent variable. Any measurement errors in earnings will bias negatively the income effect on the savings rate, which contains annual earning in the denominator. ${ }^{27}$

\footnotetext{
${ }^{25}$ Note that any transfers received from siblings are absorbed in the income variable, which is included in the saving specification.

${ }^{26}$ However, whether or not a parent is in a skilled occupation is a powerful predictor of income. Table A1 in the Appendix reports estimates, using the older respondents in the CTS aged 46-60, of the relationship between this occupation measure and log income. This variable combined with age explains from 13 to 18 percent of the variation in $\log$ income for these older respondents.

${ }^{27}$ Each twin was also asked to report the earnings of all other (non-twin) siblings. We thus have two reports on all siblings income. This method was first used by Ashenfelter and Krueger (1994) for eliminating measurement-error bias in the effects of schooling attainment.
} 
Finally, to take into account the concentration of zeros in the transfer dependent variables, we estimate the transfer equations using IV Tobit.

Column one of Table 6 reports the IV Tobit estimates of the out-transfer equation for sibling transfers. As expected, the higher is own income, the greater the expected amount of total transfers to siblings, with the own income effect statistically significantly different from zero. However, the set of parent and sibling variables are economically and statistically insignificant. For example, as reported in the table, the estimates indicate that a one standard deviation increase in the average income of the siblings results in a statistically and economically insignificant total transfer to siblings of $29 \mathrm{RMB}, p=0.165$. The parent transfer estimates, in the second column of Table 6 are similar own income significantly and positively affects the expected amounted of transfers remitted to parents, but the parent and sibling variables are individually and jointly statistically and economically insignificant. These results thus imply that a key assumption of our strategy for identifying the effect of co-residence on individual saving rates is not rejected.

\section{B. Estimates of the effects of co-residence on the savings rates of the young. The first column of Table 7} reports OLS estimates of the effects of own annual income (respondent plus spouse income if any) and co-residence on individual (or individual plus spouse) savings for respondents aged 25-35 with at least one living parent. The estimates indicate that individual or couple saving rates are higher among the young when they co-reside, although the negative sign of the own income effect is contrary to theory. This is consistent with measurement error in own income biasing the coefficient on the ratio of savings to income negatively. Indeed, when we use the instruments, including the twin's income cross-reports and the sibling and parent variables, to predict both income and co-residence the own income effect on the savings becomes positive and statistically significant, and the coefficient on coresidence increases almost fivefold, as reported in the second column of the table. The first-stage estimates for own income and co-residence are reported in columns three and four respectively, and the diagnostic statistics for identification are strong. The IV point estimate for co-residence suggests that if a young person or couple co-resides with parents, the saving rate is increased by 24 percentage points or by $66 \%$ at the sample mean. Given the point estimate of the effect of own income on the savings rate, the co-residence effect on savings is equivalent to that from an increase in income of 4.5 standard deviations. Thus, co-residence is a major factor enabling the young to enhance their savings.

We can use our IV estimates of the effects of the housing price on co-residence for the young in Table 4 and our IV estimates of the effect of co-residence on the savings rate of the young to compute how much the young savings rate would decline if the China housing price were reduced to 
that of the United States in terms of affordability. The estimates in (Fang et al., 2015)) and (Cheng et al., 2014)) suggest that the ratio of the housing price to disposable income in China is about 2.3 times that in the United States. The IV point estimate in Table 4 indicates that a reduction of the China housing price to eliminate the US-China housing price gap would lower the co-residence rate by $85 \%$, and thus, given the estimate of the co-residence effect on the savings rate in Table 7, would lower the savings rate of the young by 8.6 percentage points or by $21 \%$. Given our finding that the savings rates of heads aged 35-44, who are not selective, are unaffected by changes in housing prices, this reduction in the housing price would put the young savings rate just below that of the middle-aged.

C. Do the savings of the older parents decline due to co-residence? Our finding that adult children who co-reside with parents, for given own income, enjoy higher savings rates indicates that the young benefit from co-residence, consistent with the model. But do they do so at the expense of their parents, as implied by our findings using aggregate household savings rates by head's age? We can also use the CTS data to compare the individual savings of parents by whether they co-reside with their adult children. The CTS does not provide direct information on savings for the parents of the young respondents. However, we can look at the savings and co-residence of the older twins (aged 45 and above) who are parents of adult children to see if their individual savings are elevated or reduced when they co-reside with at least one of their adult children. $65.2 \%$ of the respondents with adult children are living with an adult child. If by co-residing with their children living costs of parents are significantly increased, then their savings should be reduced, net of own income.

The CTS also provides earnings information for all of the children of the respondent twins. Thus we can estimate the determinants of the savings of old parents in the context of the family model using a specification and identification strategy similar to that used to estimate the effects of co-residence on savings for the young, replacing average sibling income by average children income. ${ }^{28}$ The IV estimates of the determinants of the savings rates of respondent twins aged 45-60 with at least one adult child aged 25 and above are reported in column one of Table 8 . As can be seen, the estimates indicate that co-residence reduces the individual savings rate of the old, consistent with the old providing subsidies to the co-residing young that go beyond rent subsidization. This result is also consistent with the findings in Table 5 that a higher housing price, which is associated with a higher incidence of inter-generational co-residence, reduces the household savings rates of the old who have

\footnotetext{
${ }^{28}$ Almost none of the older twins have living parents. The only missing variables are those for the siblings, but the data indicate that few siblings aged 45-60 co-reside with each other.
} 
adult children just as much as it reduces the savings rates of the old without children. We thus find that parents, in contrast to their young adult children, experience a direct financial cost from intergenerational co-residence.

\section{Conclusion}

In many countries of the world the co-residence of young adults aged 25-34 with their parents is common and in some countries the savings rates of these age groups exceeds those of the middle-aged contrary to the standard model of life-cycle savings. In this paper we examined the role of housing prices in affecting the living arrangements of adult family members and raising the savings rate of the young. Using unique data from China that enabled the re-construction of whole families and identified individual savings regardless of who within the family co-resides in the same household, and exploiting the Chinese government rules determining the supply of land for residential housing, we found that increases in housing prices significantly increase inter-generational co-residence and elevate the savings rates of the young relative to the middle-aged, conditional on income, in part due to the subsidies to the young from sharing housing with parents. We found in particular that the savings rates of those aged 25-34 were substantially increased if they co-resided with parents, with the parents' savings rates negatively affected by co-residence. We also found that the positive effect of the price of housing on the savings rates of heads of households who are young is due solely to selection, as higher housing prices make it more difficult for those with low incomes to live apart from parents. Based on our estimates of the effects of housing prices on co-residence and the effects of co-residence on individual savings, we find that the savings rates of the young in China would be $21 \%$ lower if housing prices were at the same ratio to disposable incomes as that observed in the United States.

Our empirical results indicating that co-residence, net of own income and all family characteristics, affects the savings of the young but not the old call into question methodologies that attempt to identify individual savings behavior in joint households based on the assumption that household structure and individual age patterns of consumption are independent. More fundamentally, the estimates suggest that individual-based theories of savings behavior, which ignore extended family interactions, are inadequate for explaining life-cycle patterns of savings in many countries of the world where co-residence of young and old is common. The findings also point to the limitations of household, rather than family-based, survey data when important decisions on living arrangements and savings and perhaps transfers are coordinated within an extended family. 


\section{References}

Altonji, Joseph G., Fumio Hayashi and Laurence J. Kotlikoff (1992). " Is the Extended Family Altruistically Linked? Direct Tests Using Micro Data.” The American Economic Review 82 (5): 1177-1198

Ashenfelter, Orley and Alan Krueger (1994). "Estimates of the Economic Return to Schooling from a New Sample of Twins." The American Economic Review 84(5): 1157-1173.

Browning, Martin and Thomas F. Crossley (2001). "The Life-Cycle Model of Consumption and Saving." Journal of Economic Perspectives 15(3): 3-22.

Cai, Zongwu, Mitali Das, Huaiyu Xiong, and Xizhi Wu (2006). "Functional Coefficient Instrumental Variables Models." Journal of Econometrics 133 (1): 207-241.

Census Bureau (2018). Current Population Survey. Housing Vacancy Survey.

Chen, Qin and Zheng Song (2014). "Accounting for China's Urbanization." China Economic Review 30: 485-494.

Cheng,Ing--Haw, Sahil Raina and Wei Xiong (2014). "Wall Street and the Housing Bubble." The American Economic Review 104: 2797---2829.

Costa, Dora L. (1997). "Displacing the Family: Union Army Pensions and Elderly Living Arrangements." Journal of Political Economy 105(6): 1269-1292.

Dynan, Karen E., Jonathan Skinner, and Stephen P. Zeldes (2004). "Do the Rich Save More?". Journal of Political Economy 112 (2): 397-442.

Deaton, Angus and Christina Paxson (2000). "Growth and Savings Among Individuals and Households." Review of Economics and Statistics 82(2): 212-225.

Edmonds, Eric V., Kristin Mammen, and Douglas L. Miller. (2005). "Rearranging the Family? Income Support and Elderly Living Arrangements in a Low-Income Country." The Journal of Human Resources 40(1): 186-207.

Ermisch John (1999). "Prices, Parents, and Young People's Household Formation." Journal of Urban Economics 45(1), 47-71.

Fang, Hanming, Quanlin Gu, Wei Xiong and Li-An Zhou. (2015) "Demystifying the Chinese Housing Boom.” NBER Working paper No. 21112.

Gan, Li, Qing He, Ruichao Si, Daichun Yi (2019). "Relocating Migrants and Redefined Migrants: A New Perspective on Urbanization in China.” Working paper, Texas A\&M University.

Han, Jun, Runjuan Liu and Junsen Zhang (2012). "Globalization and Wage Inequality: Evidence from Urban China," Journal of International Economics 87(2): 288-297. 
Hanewald, Katja., Hazel Bateman, Hanming Fang, and Shang Wu. (2019). "Is There a Demand for Reverse Mortgages in China? Evidence from Two Online Surveys.” NBER Working Paper No. 25491.

Hayashi, Fumio (1986). "Why is Japan's Saving Rate So Apparently High?" In NBER Macroeconomics Annual 1986, Cambridge, Massachusetts: The MIT Press: 147-210.

Hayashi, Fumio (1997). Understanding Saving: Evidence from the United States and Japan. Cambridge, Massachusetts: The MIT Press.

Hayashi, Fumio, Takatoshi Ito, and Joel Slemrod (1988). "Housing Finance Imperfections, Taxation, and Private Saving: A Comparative Simulation Analysis of the United States and Japan." Journal of the Japanese and International Economies 2(3): 215-238

Huang, Wei, Xiaoyan Lei, and Yaohui Zhao (2016). "One Child Policy and the Rise of Man-Made Twins." Review of Economics and Statistics 98(3):467-476.

Jappelli, Tullio, and Franco Modigliani (2005). "The Age-Saving Profile and the Life-Cycle Hypothesis." In The Collected Papers of Franco Modigliani, Volume 6. Cambridge, Massachusetts: The MIT Press: 141-172.

Kaplan, Greg (2012). "Moving Back Home: Insurance against Labor Market Risk.” Journal of Political Economy 120 (3): 446-512.

Lee, Kwan Ok and Gary Painter (2013). "What Happens to Household Formation in a Recession?" Journal of Urban Economics 76, 93-109.

Li, Hongbin, Pak Wai Liu, Junsen Zhang, and Ning Ma (2007). "Economic Returns to Communist Party Membership: Evidence from Urban Chinese Twins." The Economic Journal 117(523): 1504-1520.

Li, Hongbin, Mark R. Rosenzweig and Junsen Zhang (2010). "Altruism, Favoritism, and Guilt in the Allocation of Family Resources: Sophie's Choice in Mao's Mass Send Down Movement." Journal of Political Economy 118(1): 1-38.

Manacorda, Marco and Enrico Moretti. (2006). "Why Do Most Italian Men Live with Their Parents? Intergenerational Transfers and Household Structure." Journal of the European Economic Association 4(4): 800-829.

Noguchi, Yukio (1994) "Land Prices and House Prices in Japan." in Housing Markets in the United States and Japan. Yukio Noguchi and James M. Poterba, editors. University of Chicago Press: 11 - 28.

Richards, Anthony (2008). "Some Observations on the Cost of Housing in Australia." http://www.rba.gov.au/speeches/2008/sp-so-270308.html.

Rosenzweig, Mark R. and Kenneth I. Wolpin (1993). "Intergenerational Support and the Life-Cycle Incomes of Parents and Adult Sons," Journal of Labor Economics 11 (1): 84-112. 
Rosenzweig, Mark R. and Junsen Zhang (2013). "Economic Growth, Comparative Advantage, and Gender Differences in Schooling Outcomes: Evidence from the Birthweight Differences of Chinese Twins," Journal of Development Economics 104: 245-260.

Ruggles, Steven, and Misty Heggeness (2008). "Inter-generational Co-residence in Developing Countries." Population and Development Review 34(2): 253-281.

Wang, Shing-Yi (2011). "State Mis-allocation and Housing Prices: Theory and Evidence from China." The American Economic Review 101(5): 2081-2107.

Wei, Shang-Jin, and Xiaobo Zhang (2011). "The Competitive Saving Motive: Evidence from Rising Sex Ratios and Savings Rates in China." Journal of Political Economy 119(3): 511-564.

Wu, Jing, Joseph Gyourko, and Youngheng Deng (2012). "Evaluating Conditions in Major Chinese Housing Markets." Regional Science and Urban Economics 42(3): 531-543.

Zhang, Junsen, Yaohui Zhao, Albert Park and Xiaoqing Song (2005). "Economic Returns to Schooling in Urban China, 1988 to 2001." Journal of Comparative Economics 33: 730-752. 


\section{Appendix A}

Proof of Proposition 1 that $S_{k, N C}^{2 *}<S_{k, C}^{2 *}$.

For this to be true the following must also be true:

$$
C_{k, N C}^{2 *} \leq C_{k, C}^{2 *} \leq C_{k, N C}^{2 *}+\pi h
$$

Proof of the first inequality:

Given the assumed constant income stream for the young, it must be true that optimized consumption is equal across periods for the non co-resident $C_{k, N C}^{2_{*}}=C_{k, N C}^{3_{*}}$. Moreover, for the coresident young in period $2 C_{k, C}^{2 *}<C_{k, C}^{3 *}$ because of the disutility of co-residence.

The second inequality can be proved as follows:

Assume that $C_{k, C}^{2_{*}}>C_{k, N C}^{2_{*}}+\pi h$, then we have

$$
C_{k, C}^{3_{*}}>C_{k, C}^{2_{*}}>C_{k, N C}^{2 *}+\pi h
$$

from the first inequality. Thus it follows that

$$
C_{k, C}^{2_{*}}+C_{k, C}^{3_{*}}>2 C_{k, N C}^{2_{*}}+2 \pi h,
$$

Note that the disposable income, denoted as $W_{d}$, under either regime is labor income ( E $E(1+\delta)$. And the disposable income is used for consumption and housing services. Under the non-coresidence regime, $C_{k, N C}^{2_{*}}+C_{k, N C}^{3_{*}}+2 \pi h=W_{d}$. Because housing services are purchased in both periods 2 and 3 in the non co-residence regime, it must hold that $W_{d}=C_{k, N C}^{2 *}+C_{k, N C}^{3_{*}}+2 \pi h=2 C_{k, N C}^{2_{*}}+2 \pi h=W_{d}$, which in turn implies that $C_{k, C}^{2 *}+C_{k, C}^{3 *}+\pi h>C_{k, C}^{2 *}+C_{k, C}^{3_{*}^{*}}>W_{d}$. This is a contradiction. Thus $C_{k, C}^{2 *}<C_{k, N C}^{2 *}+\pi h$, which leads to $S_{k, C}^{2 *}>S_{k, N C}^{2 *}$. That is, the optimal savings at period 2 under the co-residence regime is larger than that under the non-co-residence regime.

\section{Appendix B}

Proof that an increase in the cost of housing services increases young savings in the co-residence regime but not in the non-co-residence regime.

Optimal savings in the non-co-resident and co-resident regimes are given by

$$
\begin{gathered}
S_{k, N C}^{2 *}=E w-C_{k, N C}^{2 *}-\pi h, \\
S_{k, C}^{2 *}=E w-C_{k, C}^{2 *} .
\end{gathered}
$$

To understand the impact of higher housing cost on young savings in period 2, we derive the partial derivative of optimized consumption $C_{k}^{2 *}$ with respect to $\pi_{k}$.

For the non-co-residence regime $C_{k, N C}^{2 *}$ and $C_{k, N C}^{3 *}$ are determined using

$$
\begin{gathered}
U_{k 1, N C}^{2 *}=U_{k 1, N C}^{3 *}, \\
C_{k, N C}^{2 *}+C_{k, N C}^{3 *}+2 \pi h=E w(1+\delta) .
\end{gathered}
$$

so that $C_{k, N C}^{2 *}=C_{k, N C}^{3 *}=\mathbf{C}_{k, N C}^{*}$ and $2 d C_{k, N C}^{*}+2 h d \pi=0$, which in turn yields 


$$
\begin{aligned}
& \frac{\partial C_{k, N C}^{*}}{\partial \pi}=-h, \\
& \frac{\partial S_{k, N C}^{2_{*}}}{\partial \pi}=0 .
\end{aligned}
$$

Housing costs have no impact on the optimal savings in period 2 for the young in the non-coresidence regime. This is because housing costs and consumption are equal across periods. In the coresidence regime, however, a rise in the housing cost does not affect disposable income $E w(N)+\tau$ in period 2 but decreases resources available for consumption in the third period. Savings must therefore increase in period 2 to maintain the equality of marginal utilities across periods.

\section{Appendix C}

Proof that an increase in parents' income increases the relative utility of co-residence.

The marginal impact of parents' income, either in period 1 or 2 , on family utility $V$ is $\lambda_{1}$, the Lagrangian associated with the parent income constraint. It is easy to show that $\lambda_{1}=U_{3}^{1}=U_{p 1}^{2}=U_{p 1}^{3}$. Under the non-co-residence regime we have

$$
\frac{\partial^{N C}}{\partial Y_{p}}=\lambda_{1}\left|\mathbf{C}_{p, N C}^{*}=U_{p 1}^{2}\right| \mathbf{C}_{p, N C}^{*}=U_{p 1}^{3} \mid \mathbf{C}_{p, N C}^{*} .
$$

Similarly, under the co-residence regime

$$
\begin{aligned}
& \frac{\partial V^{C}}{\partial Y_{p}}=\left[\lambda_{1}+U_{k 2}^{2} h \delta_{2}\left(N, Y_{p)}\right] \mid \mathbf{C}_{p, k, C}^{*}\right. \\
& =\left[U_{p 1}^{2}+U_{k 2}^{2} h \delta_{2}\left(N, Y_{p)}\right] \mid \mathbf{C}_{p, k, C}^{*}\right. \\
& =\left[U_{p 1}^{3}+U_{k 2}^{2} h \delta_{2}\left(N, Y_{p)}\right] \mid \mathbf{C}_{p, k, C}^{*}\right.
\end{aligned}
$$

where $\mathbf{C}_{p, k}^{*}$ indicates the vector of the optimal consumption levels of the parents and kids. Then

$$
\begin{aligned}
\Delta D V= & \Delta V^{N C}-\Delta V^{C} \\
& =U_{p 1}^{2} \mid \mathbf{C}_{p, N C}^{*}-\left[U_{p 1}^{2}+U_{k 2}^{2} h \delta_{2}\left(N, Y_{p}\right)\right] \mathbf{C}_{p, k, C}^{*} \\
& =-U_{k 2}^{2} h \delta_{2}\left(N, Y_{p}\right) \mid \mathbf{C}_{k, C}^{*}>0,
\end{aligned}
$$

since $U_{p 1}^{2}\left|\mathbf{C}_{p, N C}^{*}=U_{p 1}^{2}\right| \mathbf{C}_{p, k, C}^{*}$. Thus, if the family is indifferent between regimes, an increase in parental income would lead to the choice of co-residence.

\section{Appendix D}

Proof that a permanent increase in the wage rate of the young reduces the relative utility of coresidence.

The impact of a permanent increase in the child's wage on optimized utility in either regime is always positive, and given by

$$
\frac{\partial V^{N C}}{\partial w}=\frac{\partial L}{\partial w}\left|\mathbf{C}_{N C}^{*}=2 E \lambda_{2}\right| \mathbf{C}_{N C}^{*}=2 E U_{k 1}^{3} \mid \mathbf{C}_{N C}^{*}
$$

for the co-residence regime, and 


$$
\frac{\partial V^{C}}{\partial w}=\frac{\partial L}{\partial w}\left|\mathbf{C}_{C}^{*}=2 E \lambda_{2}\right| \mathbf{C}_{C}^{*}=2 E U_{k 1}^{3} \mid \mathbf{C}_{C}^{*} .
$$

for the non-co-residence regime, where $\lambda_{2}$ is the Lagrangian associated with the income constraint of the representative child.

Because, as shown, $\mathbf{C}_{k, N C}^{*} \leq \mathbf{C}_{k, C}^{*}$, the increase in $V^{N C}$ is larger than that in $V^{C}$ when there is a wage increase, so that $\Delta D V=\Delta V^{N C}-\Delta V^{C}>0$, where $D V=V^{N C}-V^{C}$. This implies that for the family indifferent between the two regimes, a wage increase will induce a shift to non-coresidence. 
Appendix Table A1

Log Annual Income and Occupation for Working Respondents Aged 46-60, by Estimation Procedure

\begin{tabular}{lcccc}
\hline \hline Gender & \multicolumn{2}{c}{ Males } & \multicolumn{2}{c}{ Females } \\
\hline Estimation procedure & Random Effects & $\begin{array}{c}\text { Household } \\
\text { Fixed Effects }\end{array}$ & Random Effects & $\begin{array}{c}\text { Household } \\
\text { Fixed Effects }\end{array}$ \\
\hline In skill occupation & $0.515^{* * *}$ & $0.351^{* * *}$ & $0.665^{* * *}$ & $0.503^{* * *}$ \\
& $(6.76)$ & $(3.30)$ & $(8.78)$ & $(3.96)$ \\
Age & 0.0492 & - & 0.0815 & - \\
& $(0.22)$ & & $(0.34)$ & - \\
Age squared & -0.000424 & - & -0.000502 & $(0.22)$ \\
& $(0.20)$ & & .182 & .360 \\
$\mathrm{R}^{2}$ & .130 & .366 & 354 & 354 \\
$\mathrm{~N}$ & 320 & 320 & & \\
\hline
\end{tabular}

Absolute values of $t$-ratios in parentheses. $* * *$ Significant at the .01 level. 
Figure 1. Locally-Smoothed Household Savings Rates by Age of Head (Source: Chinese Household Income Project 2013)

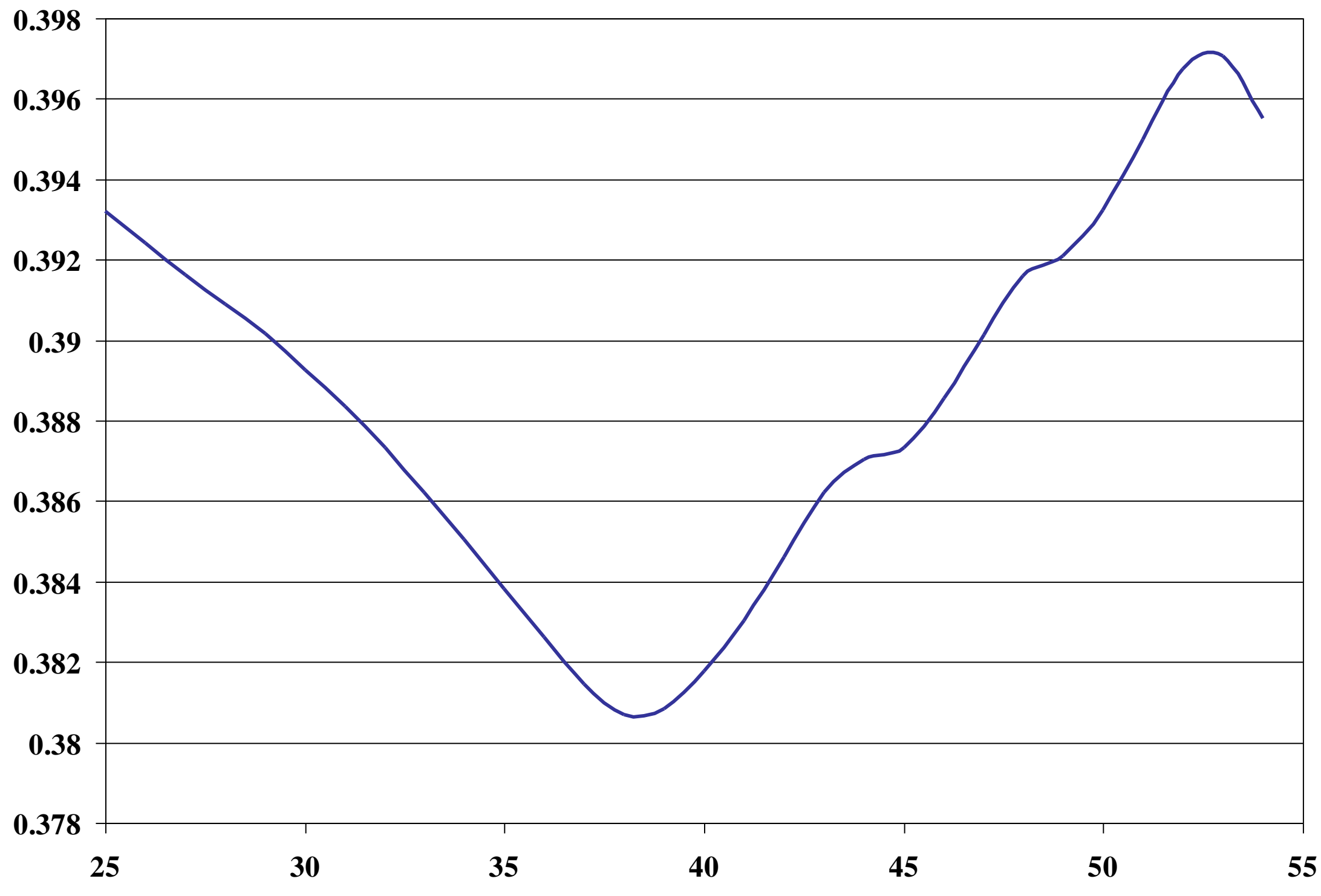


Figure 2 Locally-Smoothed Household Savings Rates by Age of Respondent

(Source: US Consumer Expenditure Survey 2013)

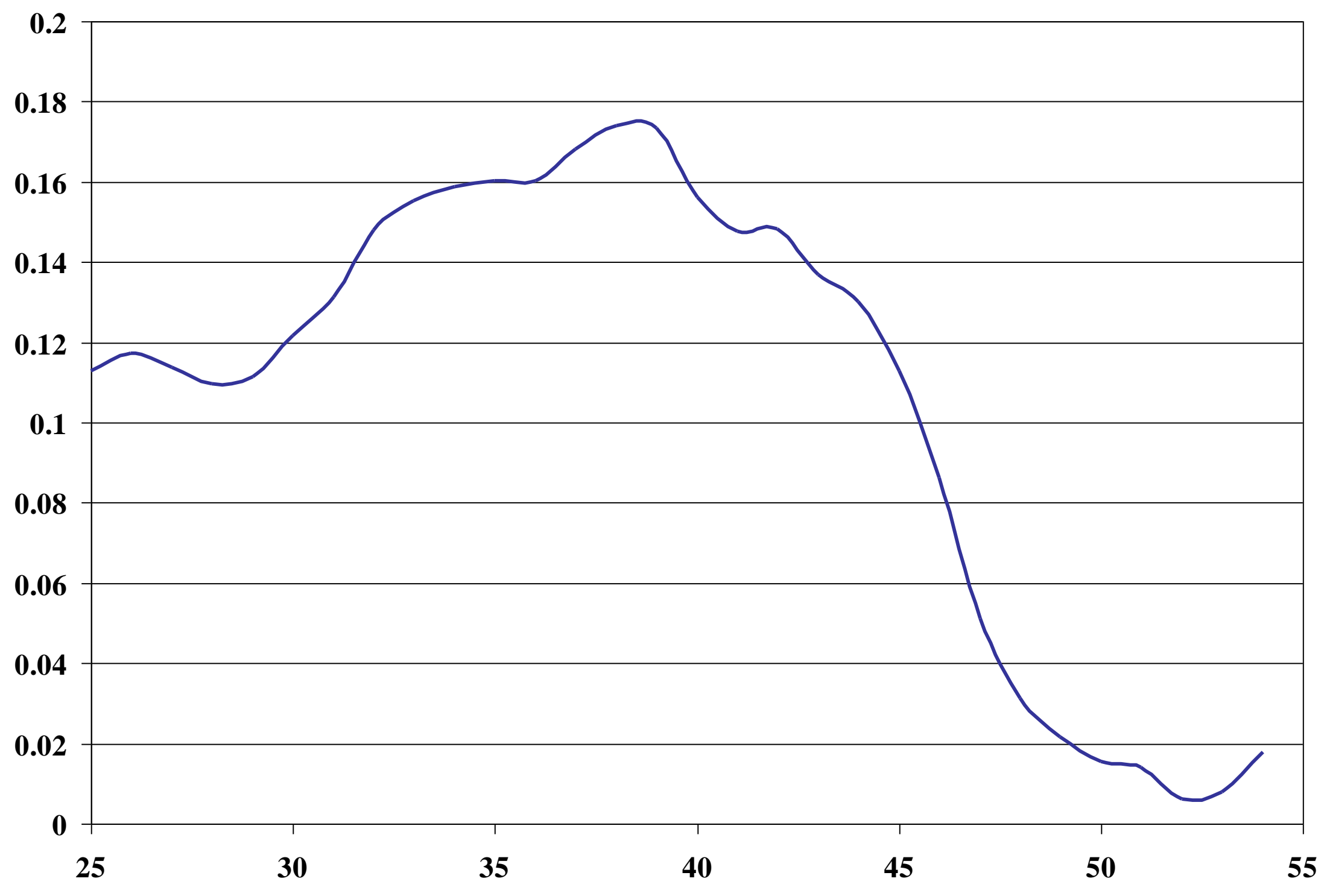


Figure 3. Fraction of Persons in Intergenerationally-Co-resident Households, by Age in China and the United States, 2013

(Sources: US Consumer Expenditure Survey and Chinese Household Income Project)

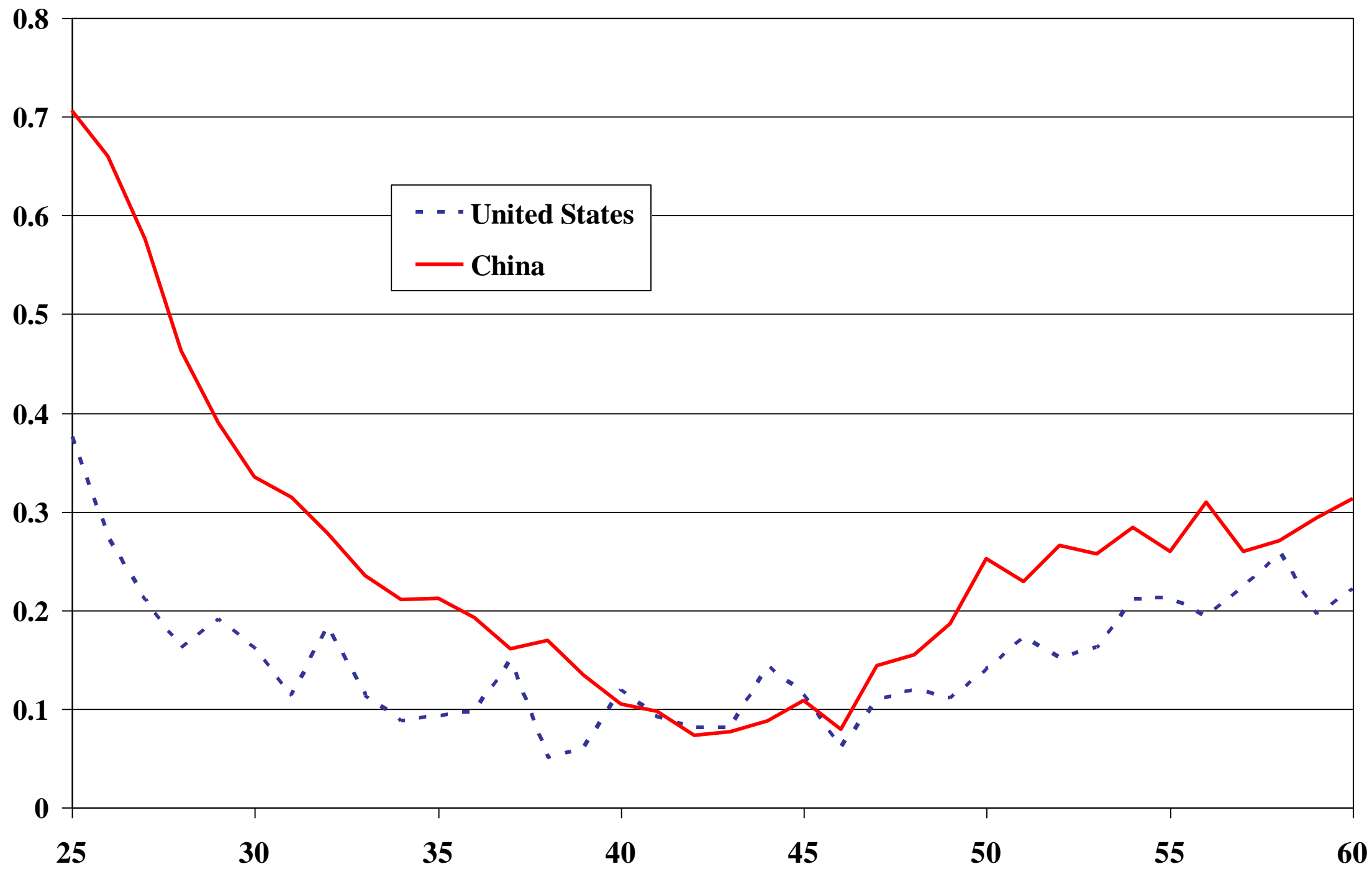


Figure 4. Headship and the Selectivity of Headship, for Males Aged 25-29, 1988 - 2009

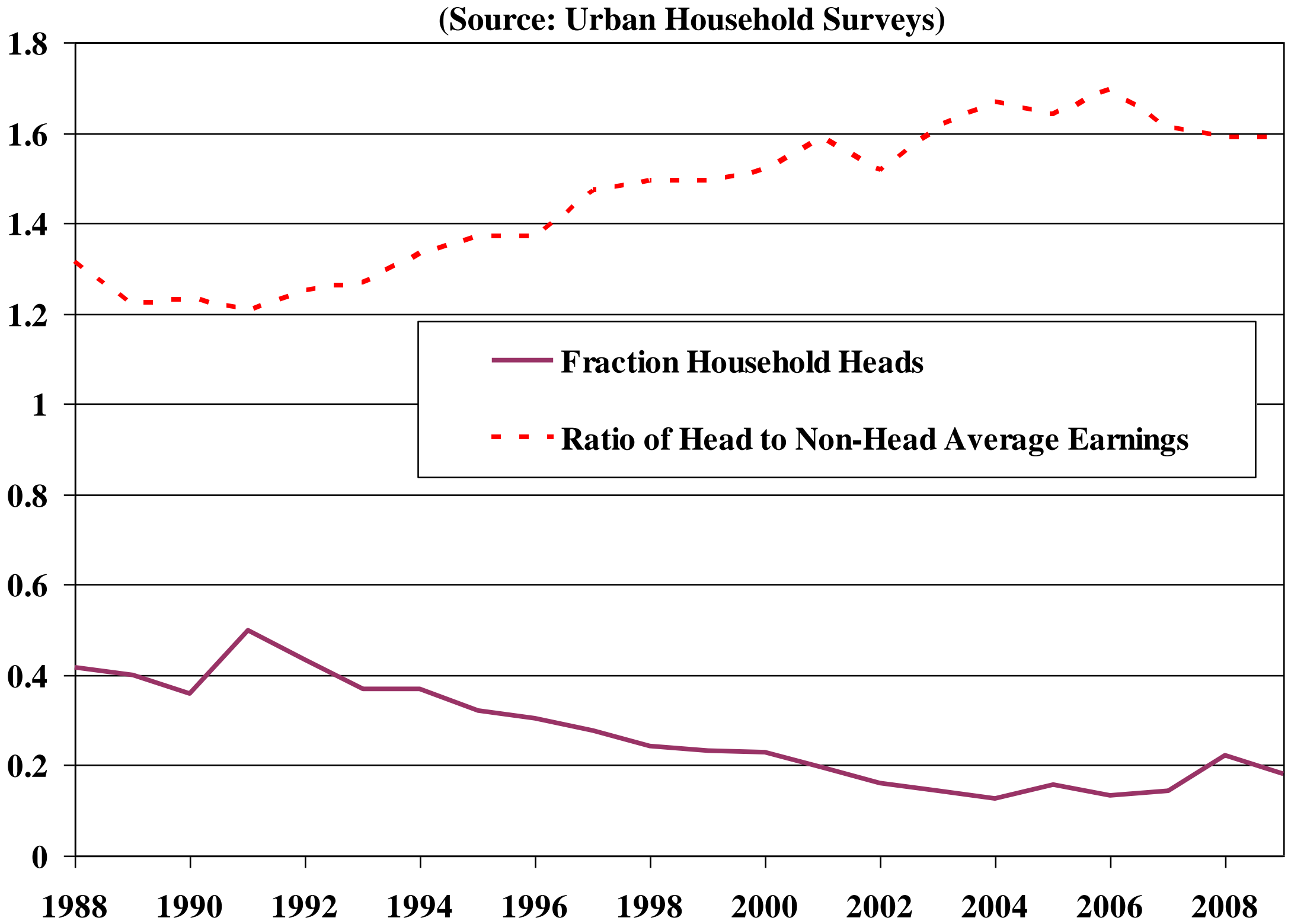


Figure 5. Fraction of Males Co-residing with Parents or Parents-in-Laws, by Age and Sample (Source: 2002 China Twin and Non-twin Surveys)

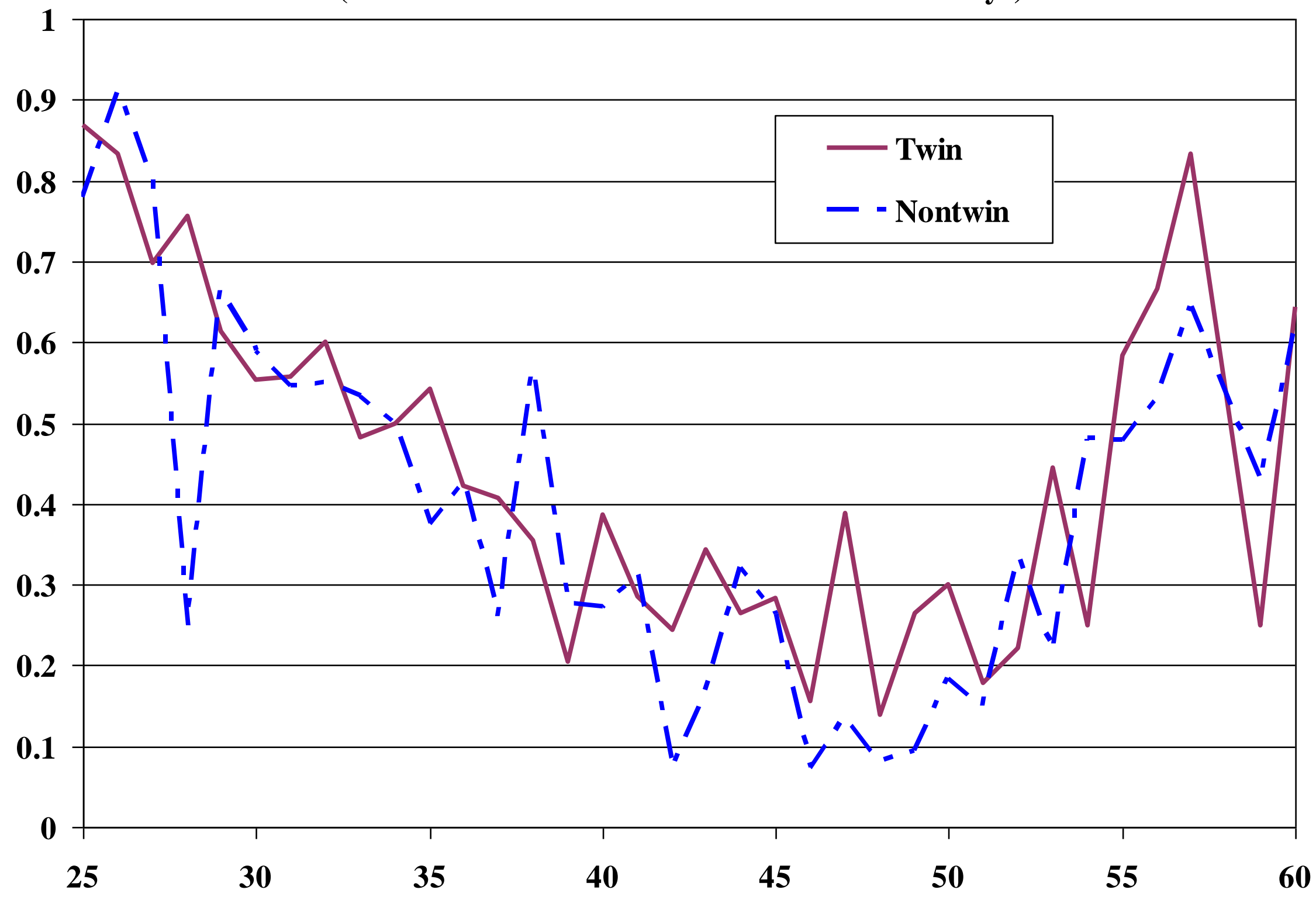


Figure 6. Individual Savings Rates, by Age and Sample

(Source: 2002 China Twin and Non-twin Surveys)

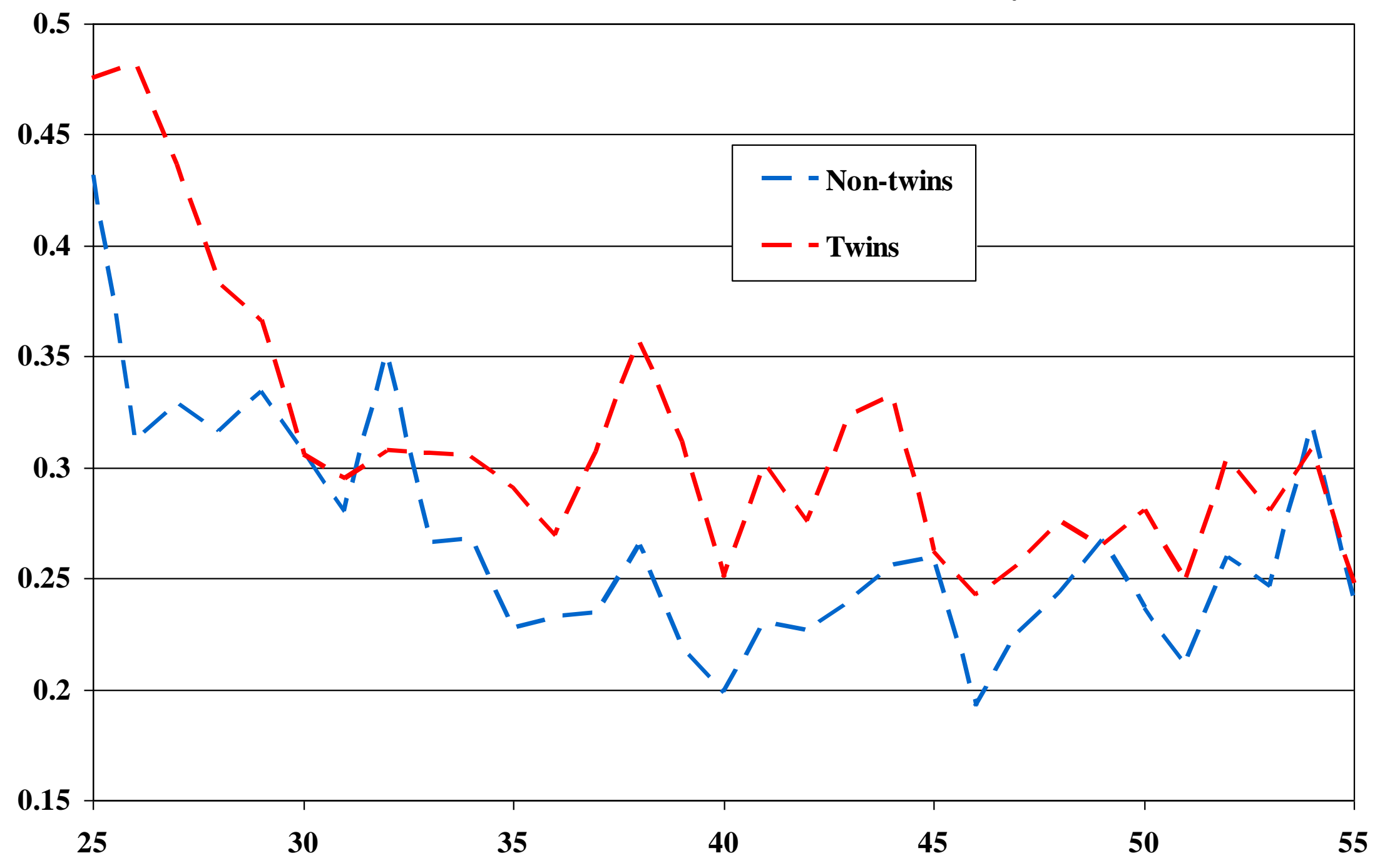


Figure 7. Male Unemployment Rates by Age and Schooling Level (Lowess-smoothed) Source: CHIP 2013

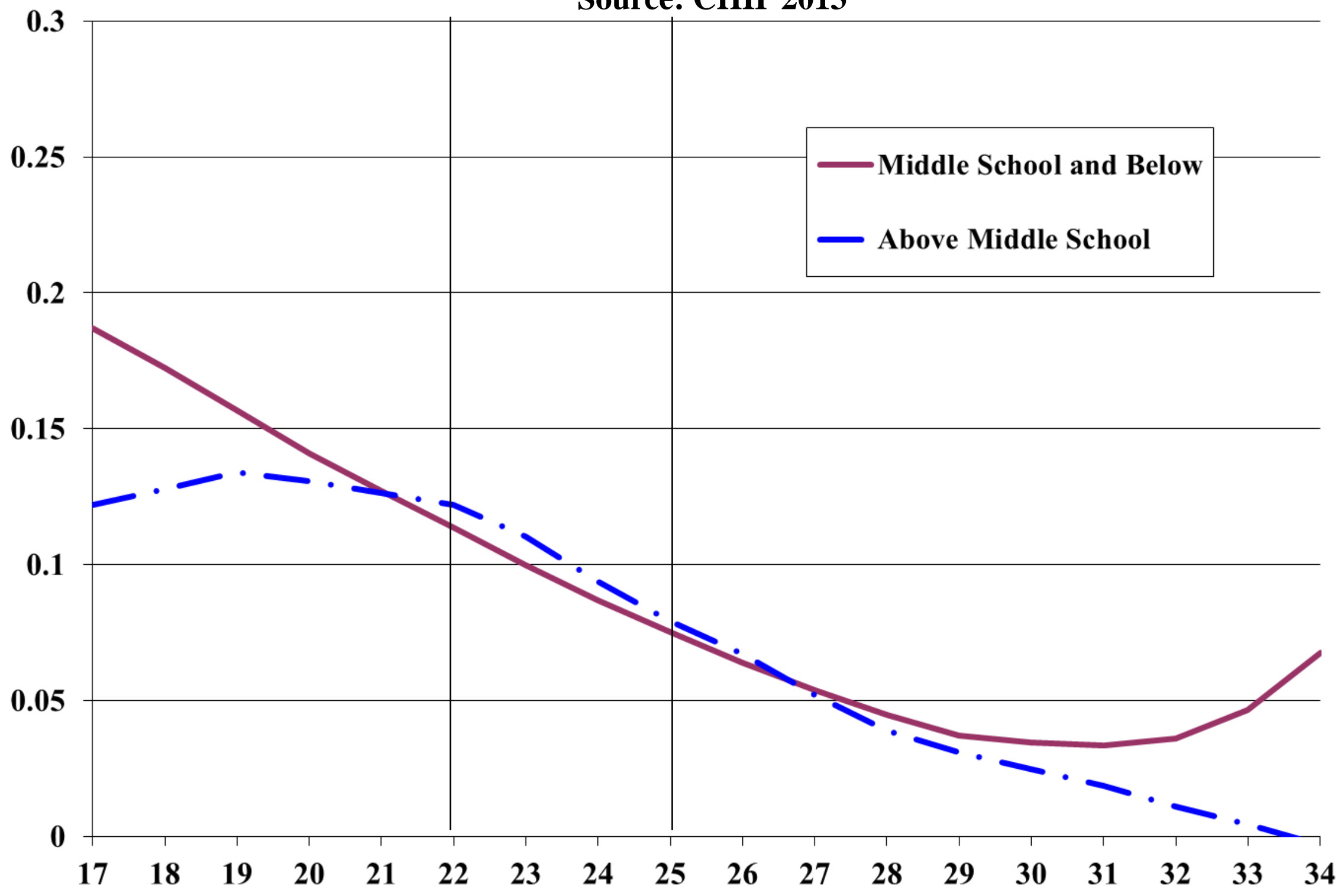


Figure 8. LWFCM Estimates of the Effect of the City Housing Price (x10-2) on the Household Savings Rate, by Head's Age, with $95 \%$ Confidence Intervals

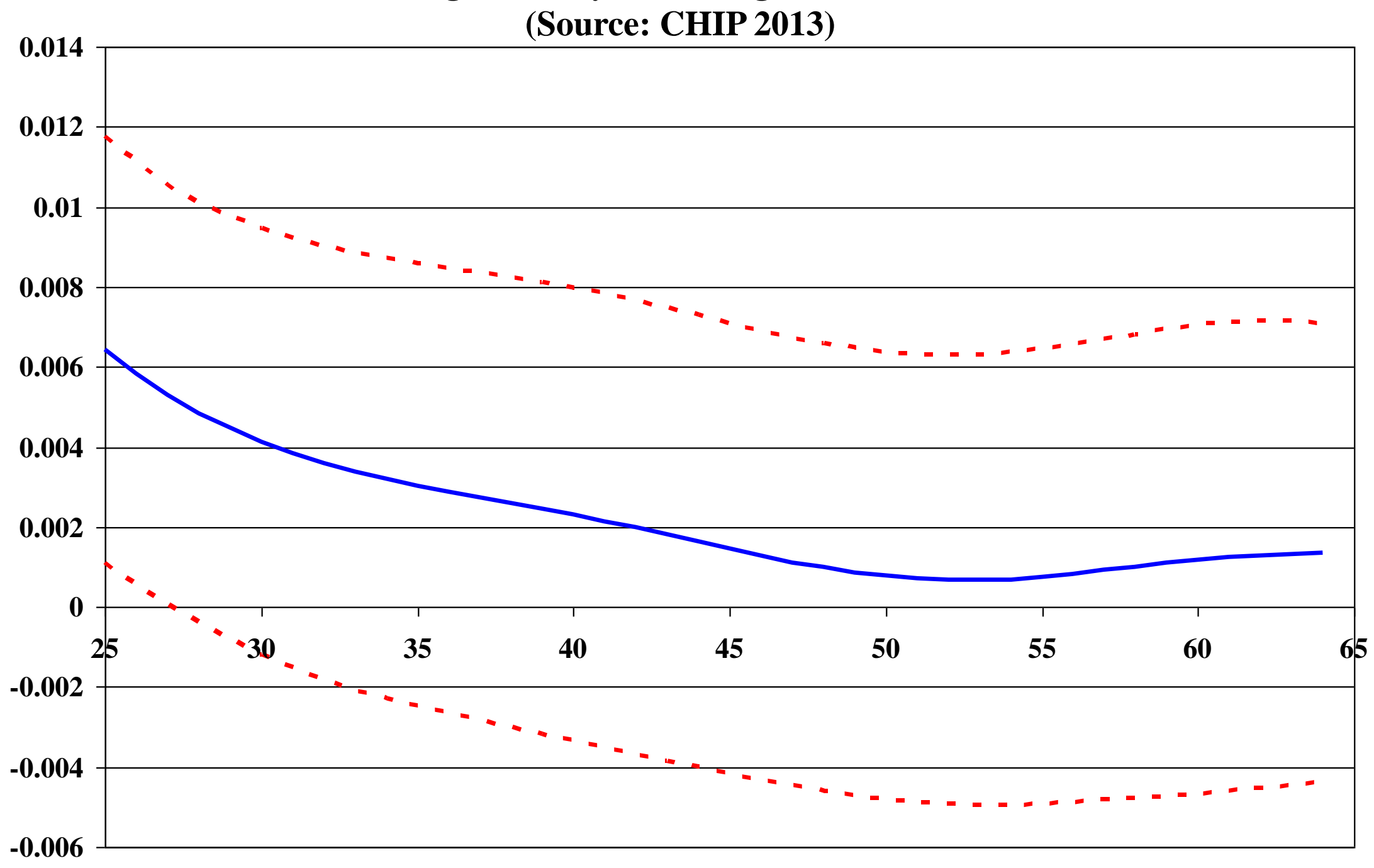


Figure 9. LWFCM Estimates of the Effect of the City Housing Price (x10-2) on Individual Income, by Age and Headship (Source: CHIP 2013)

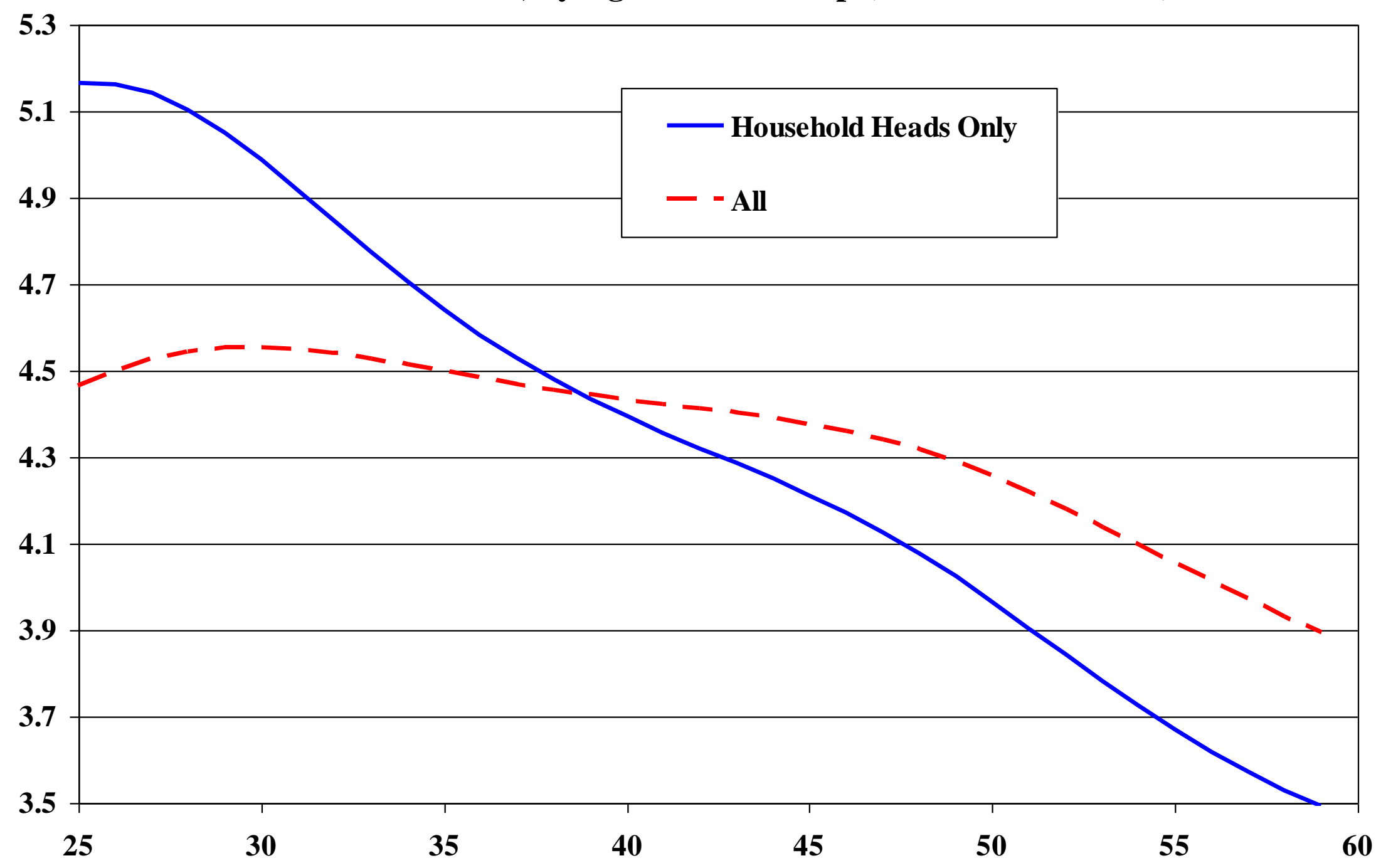


Table 1

IV and FE-IV Estimates of Quality-adjusted per-area City Housing Prices on Household Savings Rates and Incomes for Household Heads, by Head's Age Group (CHIP 2013)

\begin{tabular}{|c|c|c|c|c|c|c|c|}
\hline \multirow{3}{*}{$\frac{\text { Age group }}{\text { Dependent variable }}$} & \multicolumn{3}{|c|}{$25-34$} & \multicolumn{4}{|c|}{$25-64$} \\
\hline & \multirow{2}{*}{$\frac{\text { Saving Rate }}{(1)}$} & \multirow{2}{*}{$\frac{\text { HH Income }}{(2)}$} & \multirow{2}{*}{$\frac{\text { Saving Rate }}{(3)}$} & \multicolumn{2}{|c|}{ Saving Rate } & \multicolumn{2}{|c|}{$\mathrm{HH}$ Income } \\
\hline & & & & $(4)$ & $(5)$ & (6) & $(7)$ \\
\hline $\begin{array}{l}\text { City housing price per square } \\
\text { meter }\left(\times 10^{-3}\right)^{\mathrm{a}}\end{array}$ & $\begin{array}{l}0.0107 * * * \\
(0.00405)\end{array}$ & $\begin{array}{l}8882 * * * \\
(1270)\end{array}$ & $\begin{array}{l}0.000018 \\
(0.00592)\end{array}$ & $\begin{array}{l}0.0142 * * * \\
(0.00639)\end{array}$ & - & $\begin{array}{l}15466 * * * \\
(1988)\end{array}$ & - \\
\hline $\begin{array}{l}\text { City housing price per square } \\
\text { meter }\left(\times 10^{-3}\right) \times \text { head age }^{\mathrm{a}}\end{array}$ & - & - & - & $\begin{array}{l}-0.000276^{*} \\
(0.000146)\end{array}$ & $\begin{array}{c}-0.000339 * * * \\
(0.000147)\end{array}$ & $\begin{array}{c}-154.8 * * * \\
(32.3)\end{array}$ & $\begin{array}{l}-119.2 * * * \\
\quad(39.6)\end{array}$ \\
\hline $\mathrm{HH}$ Income $\left(\times 10^{-4}\right)$ & - & - & $\begin{array}{l}0.0119 * * * \\
(0.00292)\end{array}$ & - & - & - & - \\
\hline City fixed effects included & $\mathrm{N}$ & $\mathrm{N}$ & $\mathrm{N}$ & $\mathrm{N}$ & $\mathrm{Y}$ & $\mathrm{N}$ & $\mathrm{Y}$ \\
\hline $\mathrm{N}$ & 557 & 557 & 557 & 4503 & 4503 & 4503 & 4503 \\
\hline $\begin{array}{l}\text { Kleinberger-Paap test of } \\
\text { under-identification }\left(\chi^{2}\right)[p]\end{array}$ & $\begin{array}{c}18.18 \\
{[0.0001]}\end{array}$ & $\begin{array}{c}18.55 \\
{[0.0001]}\end{array}$ & $\begin{array}{c}16.10 \\
{[0.0003]}\end{array}$ & $\begin{array}{c}17.18 \\
{[0.0006]}\end{array}$ & $\begin{array}{c}14.17 \\
{[0.0008]}\end{array}$ & $\begin{array}{c}8.09 \\
{[0.0442]}\end{array}$ & $\begin{array}{c}14.34 \\
{[0.0008]}\end{array}$ \\
\hline $\begin{array}{l}\text { Weak instrument Anderson- } \\
\text { Rubin Wald test }\left(\chi^{2}(3)\right)[\mathrm{p}]\end{array}$ & $\begin{array}{c}9.40 \\
{[0.0091]}\end{array}$ & $\begin{array}{c}85.1 \\
{[0.0000]}\end{array}$ & $\begin{array}{c}7.49 \\
{[0.0236]}\end{array}$ & $\begin{array}{c}10.05 \\
{[0.0395]}\end{array}$ & $\begin{array}{c}7.55 \\
{[0.0229]}\end{array}$ & $\begin{array}{c}53.17 \\
{[0.0000]}\end{array}$ & $\begin{array}{c}9.64 \\
{[0.0081]}\end{array}$ \\
\hline $\begin{array}{l}\text { Hansen } J \text { overidentification } \\
\text { test }\left(\chi^{2}\right)[\mathrm{p}]\end{array}$ & $\begin{array}{c}1.765 \\
{[0.1840]}\end{array}$ & $\begin{array}{c}0.019 \\
{[0.8896]}\end{array}$ & $\begin{array}{c}2.284 \\
{[0.1307]}\end{array}$ & $\begin{array}{c}2.449 \\
{[0.2939]}\end{array}$ & $\begin{array}{c}0.207 \\
{[0.6495]}\end{array}$ & $\begin{array}{c}2.821 \\
{[0.2440]}\end{array}$ & $\begin{array}{c}0.228 \\
{[0.6329]}\end{array}$ \\
\hline
\end{tabular}

Robust standard errors clustered at the city level in parentheses. ${ }^{a}$ Endogenous variable. Excluded instruments are the re-classified urban population in 2013 and city population size in 2013. All specifications include the head's age. ***Significant at the .01 level; * Significant at the .10 level. 
Table 2

First-Stage Estimates: Quality-Adjusted Housing Prices Across Cities as a Function of the $\mathrm{In}$-situ and Total City Populations

\begin{tabular}{|c|c|c|c|}
\hline Age group & $25-34$ & \multicolumn{2}{|c|}{$25-64$} \\
\hline Variable & Q-Adjusted Housing Price & Q-Adjusted Housing Price & $\begin{array}{l}\text { Q-Adjusted Housing Price x } \\
\text { Head's Age }\end{array}$ \\
\hline In situ city population & $\begin{array}{l}-262.4 * * * \\
(120.4)\end{array}$ & $\begin{array}{l}-145.4 * * * \\
(62.2)\end{array}$ & $\begin{array}{c}4787 \\
(3748)\end{array}$ \\
\hline Total city population & $\begin{array}{l}3.109 * * * \\
(0.922)\end{array}$ & $\begin{array}{l}2.29 * * * \\
(1.120\end{array}$ & $\begin{array}{l}-27.9 * * * \\
(7.41)\end{array}$ \\
\hline In situ city population $\mathrm{x}$ head's age & - & $\begin{array}{l}-1.23 \\
(1.06)\end{array}$ & $\begin{array}{l}-308.4^{*} \\
(164.1)\end{array}$ \\
\hline Total city population $\mathrm{x}$ head's age & - & $\begin{array}{l}0.0109 * * * \\
(0.00248)\end{array}$ & $\begin{array}{l}3.42 * * * \\
(0.883)\end{array}$ \\
\hline Head's age & $\begin{array}{l}43.5 * * * \\
(21.3)\end{array}$ & $\begin{array}{l}-31.4 * * * \\
(15.9)\end{array}$ & $\begin{array}{c}379.3 \\
(579.8)\end{array}$ \\
\hline Head's age squared & - & $\begin{array}{r}0.291^{*} \\
(0.176)\end{array}$ & $\begin{array}{c}11.7 \\
(8.59)\end{array}$ \\
\hline $\begin{array}{l}\text { F-test (df,df) of excluded instruments } \\
\text { [p] }\end{array}$ & $\begin{array}{c}8.94(2,85) \\
{[0.0003]}\end{array}$ & $\begin{array}{c}27.2(4,95) \\
{[0.0000]}\end{array}$ & $\begin{array}{c}53.9(4,95) \\
{[0.0000]}\end{array}$ \\
\hline $\mathrm{N}$ & 557 & 4503 & 4503 \\
\hline
\end{tabular}

Robust standard errors clustered at the city level in parentheses. ***Significant at the .01 level; * Significant at the .10 level. 
Table 3

OLS and IV Estimates of Quality-adjusted per-area City Housing Prices and the Family Characteristics of Household Heads Aged 45-64 with Adult Children on their Probability of Intergenerational Co-Residence (CHIP 2013)

\begin{tabular}{|c|c|c|}
\hline Variable/Estimation method & OLS & IV \\
\hline $\begin{array}{l}\text { Quality-adjusted city housing price per square } \\
\text { meter }\left(\times 10^{-4}\right)^{\mathrm{a}}\end{array}$ & $\begin{array}{l}0.200^{* * *} \\
(0.0787)\end{array}$ & $\begin{array}{l}0.288^{* * *} \\
(0.133)\end{array}$ \\
\hline Mean income of adult children $\left(\times 10^{-4}\right)$ & $\begin{array}{l}-0.265^{* * *} \\
(0.0392)\end{array}$ & $\begin{array}{l}-0.271 * * * \\
(0.0395)\end{array}$ \\
\hline Mean schooling of adult children & $\begin{array}{l}-0.00613 \\
(0.00643)\end{array}$ & $\begin{array}{l}-0.00708 \\
(0.00623)\end{array}$ \\
\hline Mean age of adult children & $\begin{array}{l}-0.0530^{* * *} \\
(0.00822)\end{array}$ & $\begin{array}{l}-0.0535^{* * *} \\
(0.00806)\end{array}$ \\
\hline Proportion adult children male & $\begin{array}{l}0.185^{* * *} \\
(0.0386)\end{array}$ & $\begin{array}{l}0.186^{* * *} \\
(0.0380)\end{array}$ \\
\hline Head's income $\left(\times 10^{-4}\right)$ & $\begin{array}{c}0.00126 \\
(0.00416)\end{array}$ & $\begin{array}{l}0.000290 \\
(0.00415)\end{array}$ \\
\hline Head retired & $\begin{array}{l}-0.0618 \\
(0.0478)\end{array}$ & $\begin{array}{l}-0.0638 \\
(0.0474)\end{array}$ \\
\hline Head's schooling & $\begin{array}{l}-0.0134^{*} \\
(0.00758)\end{array}$ & $\begin{array}{l}-0.0137 * \\
(0.00734)\end{array}$ \\
\hline $\mathrm{N}$ & 944 & 944 \\
\hline Number of cities (clusters) & 96 & 96 \\
\hline F-test $(3,95)$ of excluded instruments $[\mathrm{p}]$ & - & $\begin{array}{c}33.38 \\
{[0.0000]}\end{array}$ \\
\hline $\begin{array}{l}\text { Kleinberger-Paap test of under-identification } \\
\left(\chi^{2}(3)\right)[p]\end{array}$ & - & $\begin{array}{c}8.60 \\
{[0.0352]}\end{array}$ \\
\hline $\begin{array}{l}\text { Weak instrument Anderson-Rubin Wald test } \\
\left(\chi^{2}(3)\right)[p]\end{array}$ & - & $\begin{array}{c}10.91 \\
{[0.0122]}\end{array}$ \\
\hline Hansen $J$ overidentification test $\left(\chi^{2}\right)[\mathrm{p}]$ & - & $\begin{array}{c}1.085 \\
{[0.5812]}\end{array}$ \\
\hline
\end{tabular}

Robust standard errors clustered at the city level in parentheses. ${ }^{a}$ Endogenous variable. Excluded instruments are the change in the re-classified urban population between 2012 and 2013, the total city population change between 2011 and 2013, and the city population size in 2013 . ***Significant at the .01 level; * Significant at the .10 level. 
Table 4

FE and FE-IV Estimates of Quality-adjusted per-area City Housing Prices and the Family Characteristics of All Adults Aged 25-34 with a Live Parent on their Probability of Intergenerational Co-Residence (CHIP 2002 and CHIP 2013)

\begin{tabular}{|c|c|c|}
\hline Variable/Estimation method & $\mathrm{FE}$ & FE-IV \\
\hline $\begin{array}{l}\text { Quality-adjusted city housing price per square } \\
\text { meter }\left(\times 10^{-4}\right)^{\mathrm{a}}\end{array}$ & $\begin{array}{l}0.812 * * * \\
(0.278)\end{array}$ & $\begin{array}{l}1.97 * * * \\
(0.862)\end{array}$ \\
\hline (Real 2002) income $\left(\times 10^{-4}\right)$ & $\begin{array}{l}-0.0248 * * * \\
(0.00403)\end{array}$ & $\begin{array}{l}-0.0330 * * * \\
(0.00739)\end{array}$ \\
\hline Own schooling & $\begin{array}{l}-0.00371 \\
(0.00449)\end{array}$ & $\begin{array}{l}-0.00497 \\
(0.00461)\end{array}$ \\
\hline Age & $\begin{array}{l}-0.0711 * * * \\
(0.00410)\end{array}$ & $\begin{array}{l}-0.0711 * * * \\
(0.00393)\end{array}$ \\
\hline Male & $\begin{array}{l}0.215^{* * *} \\
(0.0193)\end{array}$ & $\begin{array}{l}0.218 * * * \\
(0.0198)\end{array}$ \\
\hline Father's schooling & $\begin{array}{l}0.0217 * * * \\
(0.00234)\end{array}$ & $\begin{array}{l}0.0230 * * * \\
(0.00240)\end{array}$ \\
\hline City ratio of males to females aged 20-29 & $\begin{array}{l}0.179 * * * \\
(0.0751)\end{array}$ & $\begin{array}{l}0.226^{* * *} \\
(0.0919)\end{array}$ \\
\hline $\mathrm{N}$ & 2,587 & 2,587 \\
\hline Number of cities (fixed effects and clusters) & 41 & 41 \\
\hline F-test $(2,40)$ of excluded instruments [p] & - & $\begin{array}{c}8.81 \\
{[0.0007]}\end{array}$ \\
\hline $\begin{array}{l}\text { Kleinberger-Paap test of under-identification } \\
\left(\chi^{2}(2)\right)[p]\end{array}$ & - & $\begin{array}{c}5.84 \\
{[0.0540]}\end{array}$ \\
\hline $\begin{array}{l}\text { Weak instrument Anderson-Rubin Wald test } \\
\left(\chi^{2}(2)\right)[p]\end{array}$ & - & $\begin{array}{c}120.02 \\
{[0.0000]}\end{array}$ \\
\hline Hansen $J$ overidentification test $\left(\chi^{2}\right)[\mathrm{p}]$ & - & $\begin{array}{c}0.670 \\
{[0.4130]}\end{array}$ \\
\hline
\end{tabular}

Robust standard errors clustered at the city level in parentheses. The specifications also include whether the person is a member of the Communist Party, the age of the father, and the number of persons aged 20-29 in the sample. Cities with less than 10 persons aged 20-29 are excluded.

${ }^{a}$ Endogenous variable. Excluded instruments are the re-classified urban population in 2012 and 2013.

$* * *$ Significant at the .01 level; * Significant at the .10 level. 
Table 5

IV Estimates of Quality-adjusted per-area City Housing Prices and Family Characteristics on the Household Savings Rate of Household Heads Aged 45-64, with and without Adult Children (CHIP 2013)

\begin{tabular}{|c|c|c|c|}
\hline \multirow{2}{*}{$\begin{array}{l}\text { Children } 25-34 \\
\text { Variable }\end{array}$} & \multicolumn{2}{|c|}{ Yes } & \multirow{2}{*}{$\frac{\text { No }}{(3)}$} \\
\hline & (1) & (2) & \\
\hline $\begin{array}{l}\text { Quality-adjusted city housing price per square } \\
\text { meter }^{\mathrm{a}}\end{array}$ & $\begin{array}{l}-0.00841 \\
(0.0142)\end{array}$ & $\begin{array}{l}-0.01006 \\
(0.0134)\end{array}$ & $\begin{array}{r}-0.00953 \\
(0.0147)\end{array}$ \\
\hline Mean income of adult children $\left(\times 10^{-4}\right)$ & - & $\begin{array}{l}-0.0622 * * * \\
(0.0238)\end{array}$ & - \\
\hline Mean schooling of adult children & - & $\begin{array}{c}0.00304 \\
(0.00254)\end{array}$ & - \\
\hline Proportion adult children with no job & - & $\begin{array}{l}-0.0613 * * * \\
(0.0255)\end{array}$ & - \\
\hline Proportion adult children male & - & $\begin{array}{l}0.00993 \\
(0.0201)\end{array}$ & - \\
\hline Head's income $\left(\times 10^{-4}\right)$ & $\begin{array}{l}0.0104 * * * \\
(0.00203)\end{array}$ & $\begin{array}{l}0.0109 * * * \\
(0.00217)\end{array}$ & $\begin{array}{l}0.00975^{* * *} \\
(0.00242)\end{array}$ \\
\hline Head retired & $\begin{array}{l}-0.0230 \\
(0.0142)\end{array}$ & $\begin{array}{l}-0.0216 \\
(0.0154)\end{array}$ & $\begin{array}{l}-0.0121 \\
(0.0475)\end{array}$ \\
\hline Head's schooling & $\begin{array}{l}-0.00284 \\
(0.00278)\end{array}$ & $\begin{array}{l}-0.00316 \\
(0.00285)\end{array}$ & $\begin{array}{l}-0.00206 \\
(0.00367)\end{array}$ \\
\hline $\mathrm{N}$ & 1,019 & 1,019 & 682 \\
\hline Number of cities (clusters) & 95 & 95 & 92 \\
\hline $\mathrm{H}_{0}:$ Child characteristics $=0\left(\chi^{2}(4)\right)[\mathrm{p}]$ & - & $\begin{array}{c}12.98 \\
{[0.0114]}\end{array}$ & - \\
\hline F-test $(3,94)$ of excluded instruments $[\mathrm{p}]$ & $\begin{array}{c}79.30 \\
{[0.0000]}\end{array}$ & $\begin{array}{c}77.16 \\
{[0.0000]}\end{array}$ & $\begin{array}{c}76.08 \\
{[0.0000]}\end{array}$ \\
\hline $\begin{array}{l}\text { Kleinberger-Paap test of under-identification }\left(\chi^{2}(3)\right) \\
{[\mathrm{p}]}\end{array}$ & $\begin{array}{c}6.86 \\
{[0.0764]}\end{array}$ & $\begin{array}{c}7.41 \\
{[0.0598]}\end{array}$ & $\begin{array}{c}7.40 \\
{[0.0602]}\end{array}$ \\
\hline $\begin{array}{l}\text { Weak instrument Anderson-Rubin Wald test }\left(\chi^{2}(3)\right) \\
{[\mathrm{p}]}\end{array}$ & $\begin{array}{c}24.83 \\
{[0.0000]}\end{array}$ & $\begin{array}{c}21.04 \\
{[0.0001]}\end{array}$ & $\begin{array}{c}12.13 \\
{[0.0069]}\end{array}$ \\
\hline Hansen $J$ overidentification test $\left(\chi^{2}(2)\right)[\mathrm{p}]$ & $\begin{array}{c}3.312 \\
{[0.1909]}\end{array}$ & $\begin{array}{c}3.099 \\
{[0.2124]}\end{array}$ & $\begin{array}{c}3.838 \\
{[0.1468]}\end{array}$ \\
\hline
\end{tabular}

Robust standard errors clustered at the city level in parentheses. ${ }^{a}$ Endogenous variable. Excluded instruments are the change in the re-classified urban population between 2012 and 2013 , the total city population change between 2011 and 2013, and the city population size in 2013.***Significant at the .01 level; * Significant at the .10 level. 
Table 6

IV Tobit Estimates of the Effects of Own Earnings, Parents' Occupations and Sibling Average Income on Transfers Out: Respondents Aged 25-34 with One Alive Parent

\begin{tabular}{lcc}
\hline \hline Variable/Recipients & Siblings & Parents \\
\hline Individual income $^{\mathrm{a}}$ & $0.0284^{* * *}$ & 0.0343 \\
& $(0.0117)$ & $(0.0253)$ \\
Dad skill occupation & 49.3 & 35.9 \\
& $(136.0)$ & $(387)$ \\
Mom skill occupation & 216.1 & 135.7 \\
& $(167.0)$ & $(425.5)$ \\
Average sibling income & 0.00754 & 0.00149 \\
& $(0.00553)$ & $(0.0125)$ \\
Number of siblings & $129.4 * * *$ & 100.5 \\
& $(52.5)$ & $(159.4)$ \\
$\mathrm{H}_{0}$ : dad, mom, sib $=0, \chi^{2}(3)[\mathrm{p}]$ & 4.55 & 0.14 \\
& {$[0.208]$} & {$[0.932]$} \\
$\mathrm{d}($ transfer amount to siblings $/ \mathrm{d}(\mathrm{sd}$ & 29.2 & 10.2 \\
of average sibling income $\mid$ transfer $>$ & {$[0.165]$} & {$[0.250]$} \\
$0)$ [p] & & 877 \\
$\mathrm{~N}$ & 915 & \\
\hline
\end{tabular}

Standard errors clustered at the family level in parentheses. ${ }^{a}$ Endogenous variable. Instrument is twin's estimate of the twin's earnings. All specifications also include the gender and age of the respondent. $* * *$ Significant at the .01 level. 
Table 7

OLS and IV Estimates of the Effect of Co-Residence

on the Individual or Couple Savings Rate: Respondents Aged 25-34 with a Living Parent

\begin{tabular}{|c|c|c|c|c|}
\hline \multirow{3}{*}{$\begin{array}{l}\text { Variable } \\
\text { Co-residence }^{\mathrm{a}}\end{array}$} & OLS & IV & \multicolumn{2}{|c|}{ First stage } \\
\hline & \multicolumn{2}{|c|}{ Savings Rate } & $\begin{array}{l}\text { Couple or } \\
\text { Ind. Income }\end{array}$ & Co-residence \\
\hline & $\begin{array}{l}0.0504 * * \\
(0.0424)\end{array}$ & $\begin{array}{l}0.245^{* * *} \\
(0.0988)\end{array}$ & - & - \\
\hline $\begin{array}{l}\text { Couple or individual income } \\
\left(\mathrm{x} 10^{-4}\right)^{\mathrm{a}}\end{array}$ & $\begin{array}{c}-0.0350 * * * \\
(0.00694)\end{array}$ & $\begin{array}{r}0.0423 * \\
(0.0238)\end{array}$ & - & - \\
\hline Average sibling income $\left(\times 10^{-4}\right)$ & - & - & $\begin{array}{l}1202 \\
(837)\end{array}$ & $\begin{array}{l}-0.0199 \\
(0.0143)\end{array}$ \\
\hline $\begin{array}{l}\text { Twin's estimate of respondent } \\
\text { earnings }\left(\times 10^{-4}\right)\end{array}$ & - & - & $\begin{array}{l}6550 * * * \\
(1977)\end{array}$ & $\begin{array}{l}-0.0658 * * * \\
(0.0177)\end{array}$ \\
\hline Number of siblings & - & - & $\begin{array}{c}496.8^{*} \\
(293.7)\end{array}$ & $\begin{array}{l}-0.0283^{* * *} \\
(0.0129)\end{array}$ \\
\hline Own schooling & - & - & $\begin{array}{l}496.7 * * * \\
(164.4)\end{array}$ & $\begin{array}{l}0.0150 * * * \\
(0.00577)\end{array}$ \\
\hline Female & - & - & $\begin{array}{l}6305^{* * *} \\
(821.6)\end{array}$ & $\begin{array}{l}-0.272 * * * \\
(0.040)\end{array}$ \\
\hline $\begin{array}{l}\text { F-test }(5,477) \text { of excluded } \\
\text { instruments }[p]\end{array}$ & - & - & $\begin{array}{c}39.5 \\
{[0.0000]}\end{array}$ & $\begin{array}{c}16.8 \\
{[0.0000]}\end{array}$ \\
\hline $\begin{array}{l}\text { Kleinberger-Paap test of } \\
\text { under-identification }\left(\chi^{2}(4)\right)[p]\end{array}$ & - & $\begin{array}{c}46.7 \\
{[0.0000]}\end{array}$ & - & - \\
\hline $\begin{array}{l}\text { Hansen } J \text { overidentification } \\
\text { test }\left(\chi^{2}(3)\right)[\mathrm{p}]\end{array}$ & - & $\begin{array}{c}2.243 \\
{[0.5235]}\end{array}$ & - & - \\
\hline $\mathrm{N}$ & 906 & 906 & 906 & 906 \\
\hline
\end{tabular}

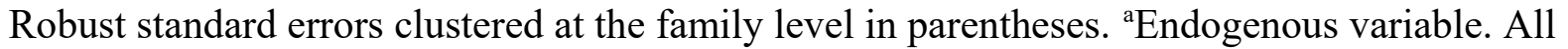
specifications also include respondent age and age squared, the father and mother's skill occupations, and (five) city fixed effects. Number of clusters $=478$. ${ }^{* * *}$ Significant at the .01 level; * Significant at the .10 level. 
Table 8

IV Estimates of the Effect of Co-Residence on the Individual or Couple Savings Rate: Respondents Aged 45-60 with at Least One Child 25+

\begin{tabular}{|c|c|c|c|}
\hline \multirow{2}{*}{$\begin{array}{l}\text { Stage } \\
\text { Variable }\end{array}$} & \multirow{2}{*}{$\begin{array}{c}\text { Second } \\
\text { Savings Rate }\end{array}$} & \multicolumn{2}{|c|}{ First } \\
\hline & & $\begin{array}{l}\text { Couple } \\
\text { Income }\end{array}$ & $\begin{array}{l}\text { Co- } \\
\text { residence }\end{array}$ \\
\hline Co-residence ${ }^{a}$ & $\begin{array}{l}-0.1195 \\
(0.1234)\end{array}$ & - & - \\
\hline $\begin{array}{l}\text { Couple or individual income } \\
\left(\mathrm{x} 10^{-4}\right)^{\mathrm{a}}\end{array}$ & $\begin{array}{c}0.0376 \\
(0.0421)\end{array}$ & - & - \\
\hline Number of adult children $25+$ & - & $\begin{array}{r}463.9 \\
(996.3)\end{array}$ & $\begin{array}{r}0.09246^{*} \\
(0.05269)\end{array}$ \\
\hline Fraction of adult children male & - & $\begin{array}{l}-4214^{* *} \\
(2073)\end{array}$ & $\begin{array}{c}0.4044 * * * \\
(0.0848)\end{array}$ \\
\hline Average adult child income $\left(\times 10^{-4}\right)$ & - & $\begin{array}{c}2858^{*} \\
(0.1721)\end{array}$ & $\begin{array}{l}-0.0618 \\
(0.0435)\end{array}$ \\
\hline Respondent schooling & - & $\begin{array}{l}1102 * * * \\
(400.5)\end{array}$ & $\begin{array}{r}-0.006740 \\
(0.01303)\end{array}$ \\
\hline Twin's estimate of respondent earnings $\left(\times 10^{-4}\right)$ & - & $\begin{array}{l}5538 * * * \\
(2245)\end{array}$ & $\begin{array}{c}0.0147 \\
(0.0501)\end{array}$ \\
\hline F-test $(5,107)$ of excluded instruments $[p]$ & - & $\begin{array}{c}7.85 \\
{[0.0000]}\end{array}$ & $\begin{array}{c}6.05 \\
{[0.0001]}\end{array}$ \\
\hline $\begin{array}{l}\text { Kleinberger-Paap test of under-identification } \\
\left(\chi^{2}(4)\right)[p]\end{array}$ & $\begin{array}{l}15.60 \\
{[0.0036]}\end{array}$ & - & - \\
\hline Hansen $J$ overidentification test $\left(\chi^{2}(3)\right)[\mathrm{p}]$ & $\begin{array}{c}4.95 \\
{[0.1758]}\end{array}$ & - & - \\
\hline $\mathrm{N}$ & 165 & 165 & 165 \\
\hline
\end{tabular}

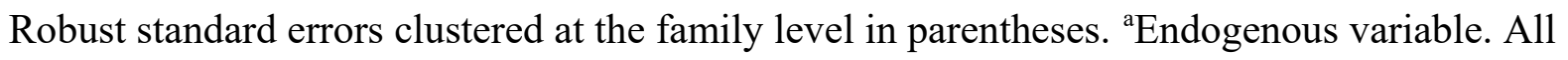
specifications also include respondent age and age squared and (five) city fixed effects. Number of clusters $=108 .{ }^{* * *}$ Significant at the .01 level; ${ }^{*}$ Significant at the .10 level. 
Table 9

OLS and IV Estimates of the Effect of Co-Residence

on Net Financial and Goods Transfers from Parents:

Respondents Aged 25-34 with a Living Parent

\begin{tabular}{lcc}
\hline \hline Variable/Estimation Method & OLS & IV \\
\hline Co-residence $^{\mathrm{a}}$ & -133.4 & $1352^{* * *}$ \\
& $(299.2)$ & $(648.7)$ \\
Daily wage $^{\mathrm{a}}$ & -3.65 & -11.7 \\
& $(5.53)$ & $(19.1)$ \\
Schooling attainment (years) & -109.6 & -100.6 \\
& $(67.54)$ & $(63.4)$ \\
Dad skill occupation & 67.5 & 11.2 \\
& $(283.2)$ & $(286)$ \\
Mom skill occupation & -137.0 & -41.8 \\
& $(275.2)$ & $(275)$ \\
Kleinberger-Paap test of under- & - & 62.3 \\
identification $\left(\chi^{2}(4)\right)$ [p] & & {$[0.0000]$} \\
Hansen $J$ overidentification test & - & 0.549 \\
$\left(\chi^{2}(3)\right)$ [p] & & {$[0.7598]$} \\
$\mathrm{N}$ & 704 & 704 \\
\hline
\end{tabular}

Standard errors clustered at the family level in parentheses. ${ }^{a}$ Endogenous variable. Instruments are twin's estimate of the twin's earnings, average sibling income, number of siblings. All specifications also include the gender and age of the respondent. ***Significant at the .01 level. 